\title{
Performance Calculations for a Boundary-Layer-Ingesting Fan Stage from Sparse Measurements
}

\author{
Stefanie M. Hirt, ${ }^{1}$ John D. Wolter, ${ }^{2}$ David J. Arend, ${ }^{3}$ and Tristan A. Hearn, ${ }^{4}$ \\ NASA Glenn Research Center, Cleveland, Ohio, 44135 \\ Larry W. Hardin, ${ }^{5}$ \\ United Technologies Research Center, East Hartford, Connecticut, 06108 \\ and \\ John A. Gazzaniga ${ }^{6}$ \\ Zin Technologies, Inc., Middleburg Heights, Ohio, 44130
}

\begin{abstract}
A test of the Boundary Layer Ingesting Inlet/Distortion Tolerant Fan was completed in NASA Glenn's 8- by 6-Foot Supersonic Wind Tunnel. Inlet and fan performance were measured by surveys using a set of rotating rake arrays upstream and downstream of the fan stage. Surveys were conducted along the $100 \%$ speed line as well as a constant exit corrected flow line passing through the aerodynamic design point. These surveys represented only a small fraction of the data collected during the test. For other operating points, data was recorded as "snapshots" without rotating the rakes which resulted in a sparser set of recorded data. This paper will discuss an approach to the analysis of these additional, lower-measurement-density data points to expand our coverage of the fan map. Several techniques will be used to enhance snapshot data and compare with survey data to assess the quality of the approach.
\end{abstract}

\section{Nomenclature}

Abbreviations

ADP Aerodynamic Design Point

AIP Aerodynamic Interface Plane

AIPRRA Aerodynamic Interface Plane Rotating Rake Array

BiCS Bidirectional Cubic Spline Interpolation

BLI Boundary Layer Ingestion

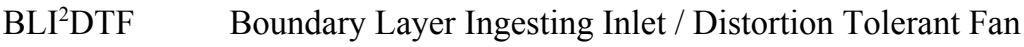

ESS Enhanced Snapshot

FE Fan-Stage Exit

\footnotetext{
${ }^{1}$ Aerospace Engineer, Inlets and Nozzles Branch, Mail Stop 5-12, 21000 Brookpark Rd, Senior Member AIAA.

${ }^{2}$ Aerospace Engineer, Inlets and Nozzles Branch, Mail Stop 5-12, 21000 Brookpark Rd, Associate Fellow AIAA.

${ }^{3}$ Aerospace Engineer, Inlets and Nozzles Branch, Mail Stop 5-12, 21000 Brookpark Rd, Associate Fellow AIAA.

${ }^{4}$ Research Aerospace Engineer, Propulsion Systems Analysis Branch, Mail Stop 5-11, 21000 Brookpark Rd, Member AIAA.

${ }^{5}$ Fellow, Thermal and Fluid Sciences, 411 Silver Lane, Associate Fellow AIAA.

${ }^{6}$ Aerospace Engineer, 21000 Brookpark Rd, Cleveland, OH 44135, Member AIAA.
} 


$\begin{array}{ll}\text { FERRA } & \text { Fan-Stage Exit Rotating Rake Array } \\ \text { GI } & \text { Guided Interpolation } \\ \text { LCS } & \text { Linear/Cubic Spline } \\ \text { PCHIP } & \text { Piecewise Cubic Hermite Interpolating Polynomial } \\ \text { SS } & \text { Snapshot (includes USS and ESS or both) } \\ \text { TAE } & \text { Total Analytical Error } \\ \text { USS } & \text { Unenhanced Snapshot }\end{array}$

Symbols

$\begin{array}{ll}\eta_{\mathrm{a}, \mathrm{S}} & \text { Fan-Stage Adiabatic Efficiency } \\ \theta & \text { Circumferential Coordinate, degrees } \\ \mathrm{f} & \text { Arbitrary Functional Value } \\ \mathrm{P}_{\mathrm{S}, \mathrm{T}} & \text { Static Pressure, Measured at Inlet Throat, PSIA } \\ \mathrm{P}_{\mathrm{T}} & \text { Total Pressure, PSIA } \\ \mathrm{P}_{\mathrm{T}}, & \text { Normalized Total Pressure, }=\mathrm{P}_{\mathrm{T}} / \mathrm{P}_{\mathrm{T}, \text { Freestream }} \\ \mathrm{r} & \text { Radial Coordinate, in. } \\ \mathrm{R}^{2} & \text { Coefficient of Determination } \\ \mathrm{T}_{\mathrm{T}} & \text { Total Temperature, } \mathrm{R} \\ \mathrm{T}_{\mathrm{T}}, & \text { Normalized Total Temperature, }=\mathrm{T}_{\mathrm{T}} / \mathrm{T}_{\mathrm{T}, \text { Frestream }} \\ \mathrm{W}_{\mathrm{C}} & \text { Corrected Weight Flow, lbm } / \mathrm{s} \\ \mathrm{W}_{\mathrm{C}, \mathrm{SS}} & \text { Corrected Weight Flow from Snapshot Measurement, lbm } / \mathrm{s}\end{array}$

\section{Introduction}

Based on system studies ${ }^{1-3}$ which showed a potential reduction in fuel burn for a hybrid wing body vehicle employing a boundary layer ingesting (BLI) propulsion system, a propulsor was designed ${ }^{4-6}$ and tested ${ }^{7-10}$ to demonstrate the feasibility of BLI technology. For these benefits to be realized, the BLI propulsor would need to be able to operate in a highly-distorted flow environment while maintaining acceptably high levels of performance and operability. The Boundary-Layer-Ingesting Inlet/Distortion Tolerant Fan (BLI $\left.{ }^{2} \mathrm{DTF}\right)$ experiment was conducted in the 8- by 6-Foot Supersonic Wind Tunnel at the NASA Glenn Research Center in November and December of 2016.

The propulsor in this experiment comprised a short non-axisymmetric inlet closely coupled to a single-stage low-pressure-ratio fan, and an uncalibrated plug-type nozzle for flow rate control. This propulsor was embedded in a raised floor to simulate the flow along the surface of the aft end of a hybrid wing body vehicle such as the N2A-EXTE hybrid wing body aircraft, shown in Fig 1. Figure 2 shows the BLI'DTF experimental setup in the 8'x6' Supersonic Wind Tunnel. 


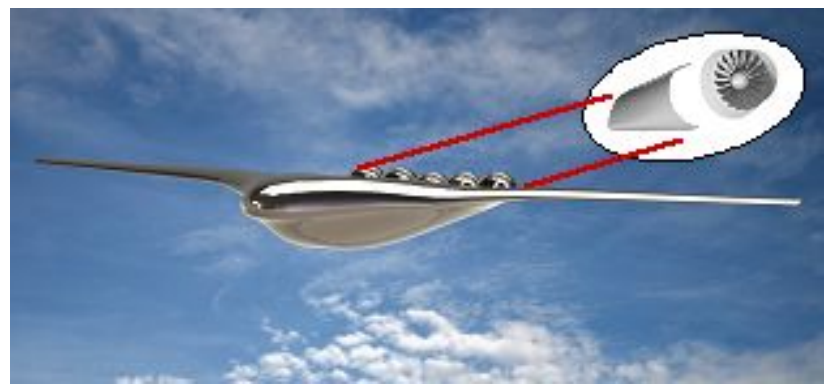

Figure 1. Hybrid wing body vehicle with boundary layer ingesting propulsion from a system study ${ }^{3}$.

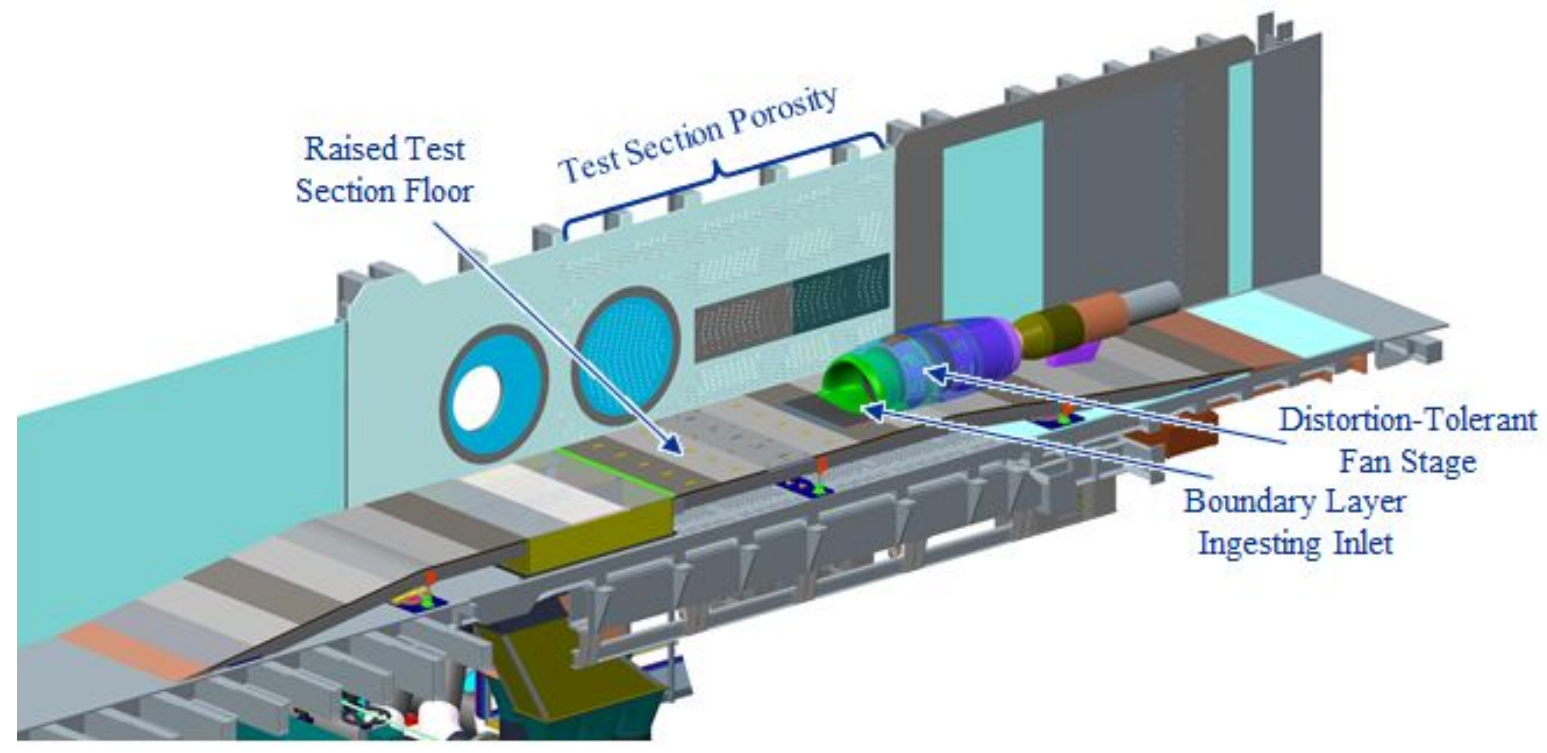

Figure 2. The BLI'DTF Experimental Setup in the 8'x6' Supersonic Wind Tunnel.

The primary research objective of the BLI'DTF wind tunnel experiment was to acquire fan-stage performance data at cruise conditions. Secondary research objectives included obtaining fan-stage performance data at other fan conditions, collecting data to determine the stall margin along the operating line, and assessing the operability of the fan over a wide range of conditions, noting areas of aerodynamic or aeromechanical instability.

A key to meeting these objectives was accurate measurement of the flow conditions upstream and downstream of the fan stage. To accomplish this, two rotating rake arrays were included in the experiment: the Aerodynamic Interface Plane Rotating Rake Array (AIPRRA) and the Fan-stage Exit Rotating Rake Array (FERRA). This paper will examine the level of accuracy that can be expected from unrotated, single-sample snapshots taken at the rotating rake array planes compared to fully-rotated, multi-sample surveys by considering several interpolation algorithms.

\section{Surveys vs. Snapshots}

A pre-test study ${ }^{8}$ showed that in order to achieve uncertainty of less than $\pm 1.5 \%$ at the aerodynamic design point (ADP), rotating rake arrays were required at the aerodynamic interface plane (AIP) and the fan-stage exit (FE) measurement plane. Furthermore this study specified the measurement density required to achieve these uncertainty levels. This density was achieved during testing by rotating the rake arrays through a defined set of angles to assemble flow property measurements on the prescribed grid. The resulting set of measurements will hereafter be referred to as a survey.

Survey data provides the most reliable, robust set of data at any condition. However the survey process is time-consuming, limiting the number of surveys which can be acquired. Hence survey data were only collected at 15 operating conditions along the $100 \%$ speed line and the line of constant exit corrected flow $(81.9 \mathrm{lbm} / \mathrm{s})$ that includes the ADP. Surveys took approximately 40 minutes to acquire. During this time conditions were monitored to ensure consistency across the survey. On average, the standard deviation of test section Mach number and corrected 
fan speed during a survey were 0.001 and 3.4 RPM, respectively. Additionally, data were normalized or corrected to freestream conditions and calculations were performed on the normalized/corrected data.

During testing, data were also taken without rotating the rake arrays. This resulted in sparse data at the rake measurement planes, which will hereafter be referred to as a snapshot. A comparison of the features of the data collected for surveys and snapshots is shown in Table 1. A much broader set of data exists in the 119 snapshots at relevant conditions, shown in Fig. 3, which were acquired over a wide range of operating conditions and include repeat measurements. These snapshots could provide important performance measurements if the errors in the data can be quantified.

In this paper, results calculated using the snapshots are compared to those calculated from the corresponding surveys. Additionally, an investigation is presented regarding whether the use of interpolation to enhance the data density of a snapshot can improve the results. For clarity, we will refer to "unenhanced snapshot" (USS) data, "enhanced snapshot" (ESS) data, and "snapshot" (SS) will be used generically, or when both are present. Because of the focus here on the methods and their accuracy, all data presented will be for conditions where a full survey was recorded to serve as a baseline.

Table 1. Comparison of features for surveys and snapshots.

\begin{tabular}{|l|c|c|}
\hline & Surveys & Snapshots \\
\hline Overall Data Density & $\begin{array}{c}\text { 936 (AIPRRA) and 1728 (FERRA) total } \\
\text { data points in the annulus }\end{array}$ & $\begin{array}{c}72 \text { (AIPRRA) and 54 (FERRA) points } \\
\text { in the annulus }\end{array}$ \\
\hline Circumferential Density & Data every $5^{\circ}$ & $\begin{array}{c}\text { Data every } 45^{\circ} \text { (AIPRRA) and } \\
40^{\circ} \text { (FERRA) }\end{array}$ \\
\hline Grid & Data points form a regular grid & Data points are irregularly spaced \\
\hline
\end{tabular}

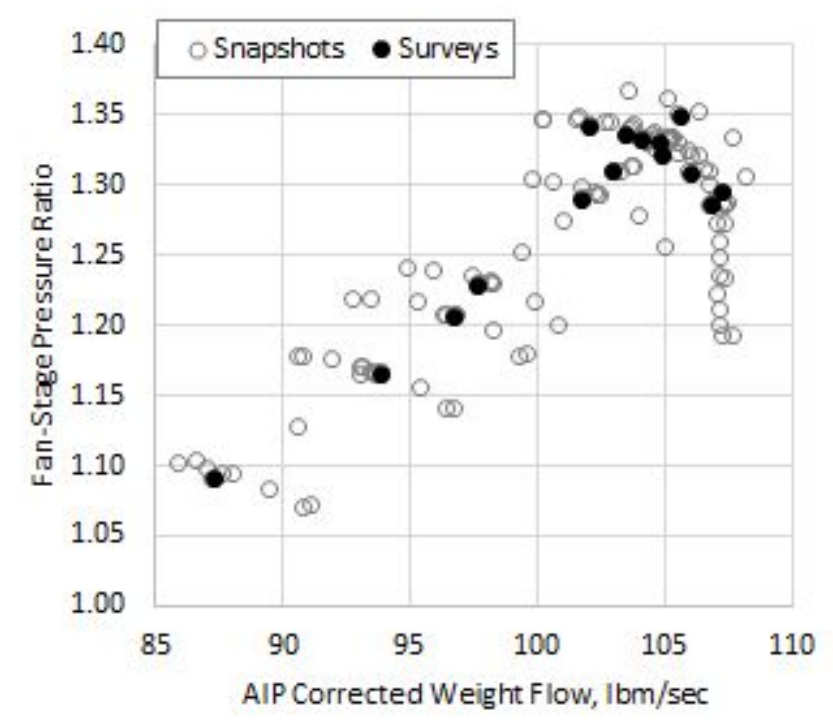

Figure 3. Available data from the BLI²DTF test.

\section{Experimental Setup}

\section{Experiment Overview and Test Conditions}

Other publications $\mathrm{s}^{7-10}$ have discussed the experimental setup and test conditions in great detail. A cutaway of the propulsor model is shown in Fig. 4 with the AIPRRA, fan, exit guide vanes, and FERRA indicated. The wind tunnel experiment included configurations with and without the AIP rakes installed as described by Hardin ${ }^{11}$. 
For all data included in this paper, the tunnel freestream Mach number was 0.78 and the boundary layer thickness approaching the inlet was $4.8 \mathrm{in}$. In this report, some data is presented normalized by freestream conditions. For this test, freestream temperature was taken to be the average of the five type E thermocouples (individual uncertainty $=0.45 \mathrm{R}$ ) mounted on rake bodies on the nacelle surface, seen in Fig. 5 . The freestream pressure was determined from a calibration curve based on the facility pressures.

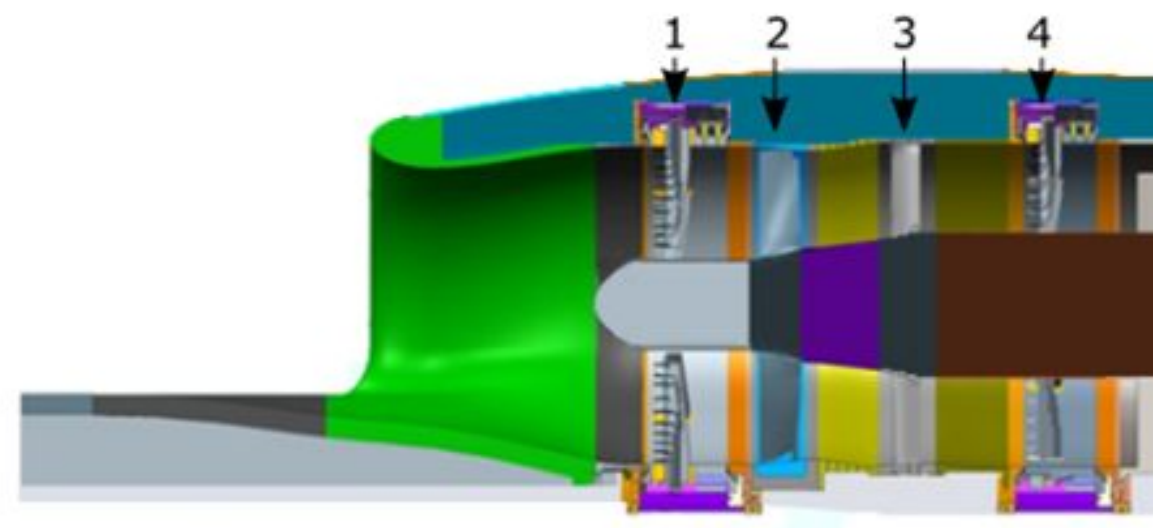

Figure 4. Cross-section of BLI²DTF Propulsor, Showing 1) AIPRRA, 2) Fan, 3) Exit Guide Vanes, and 4) FERRA.

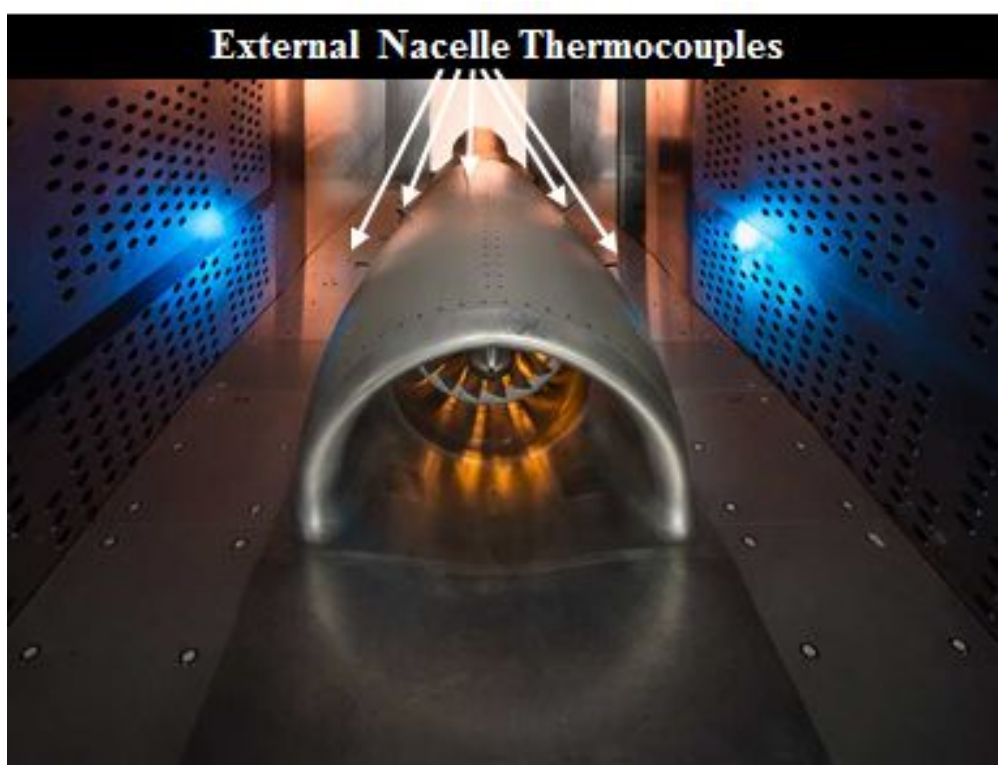

Figure 5. Photograph of the model showing the external nacelle thermocouples.

\section{Rotating Rake Array Details}

Rotating rake arrays were used at the AIP and FE planes to collect measurements of the flowfield properties. A detailed description of the rake arrays is presented by Wolter et $\mathrm{al}^{8}$. As shown in Fig. 6, the rakes were fixed to a rotatable cylindrical spool, projecting inward from the casing toward the hub. Due to space limitations, the desired radial measurement positions were spread across multiple rake types for both the AIPRRA and FERRA, and the rake array was rotated to allow each of the rake types to sample at each circumferential location. In addition to effectively increasing the radial resolution of the measurement grid, for the FERRA this approach enabled non-simultaneous measurement of total pressure and total temperature at the same locations. AIPRRA and FERRA pressure and temperature measurement uncertainties were 0.023 PSIA and $0.45 \mathrm{R}$ respectively. Note that because the AIPRRA and FERRA were at the entrance and exit of the fan stage, and no rakes were placed between the fan and exit guide vanes, only fan stage performance could be measured in this experiment. 

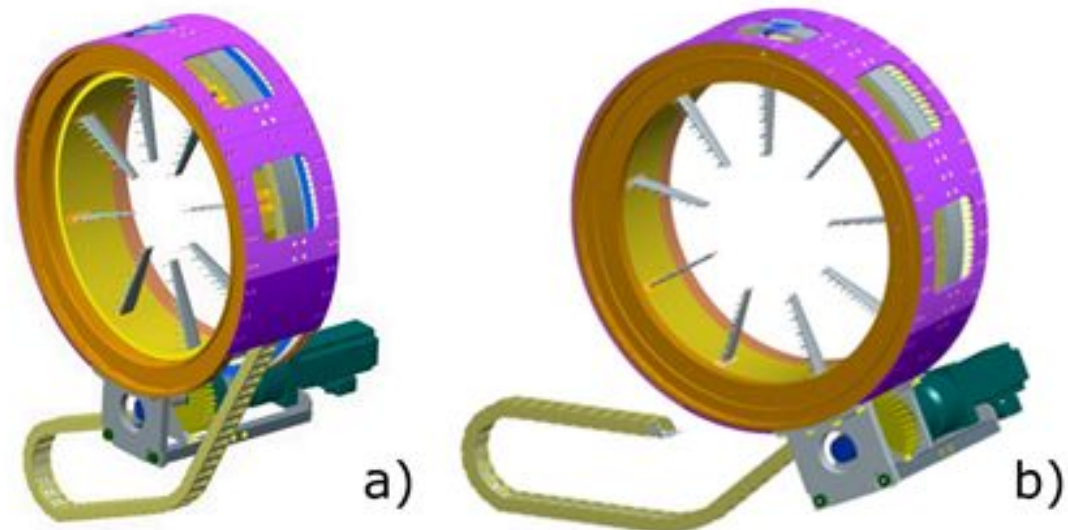

Figure 6. Rotating Rake Arrays; a) AIPRRA, b) FERRA.

There were a total of eight AIPRRA rakes consisting of two types that differed in the arrangement and spacing of the rake probes, as shown in Table 2. Each AIP rake included nine total pressure probes, with five of these set at the centers of equal-area regions for compatibility with traditional distortion parameters. Prior to the test, the total temperature at the AIP was assumed to be nearly uniform. Therefore, only one was present in each AIPRRA rake.

Table 2. Arrangement of $P_{T}$ and $T_{T}$ probes on the AIPRRA rakes.

\begin{tabular}{|c|c|c|}
\hline \multirow{2}{*}{ Radius, in } & \multicolumn{2}{|c|}{ Tube Type } \\
\cline { 2 - 3 } & $\begin{array}{c}\text { Rake A } \\
\text { (qty. 4) }\end{array}$ & $\begin{array}{c}\text { Rake B } \\
\text { (qty. 4) }\end{array}$ \\
\hline 3.492 & -- & $\mathrm{P}_{\mathrm{T}}$ \\
\hline 3.727 & $\mathrm{P}_{\mathrm{T}}$ & -- \\
\hline 4.62 & $\mathrm{P}_{\mathrm{T}}$ & $\mathrm{P}_{\mathrm{T}}$ \\
\hline 5.367 & -- & $\mathrm{P}_{\mathrm{T}}$ \\
\hline 5.962 & -- & $\mathrm{T}_{\mathrm{T}}$ \\
\hline 6.022 & $\mathrm{P}_{\mathrm{T}}$ & -- \\
\hline 6.612 & $\mathrm{P}_{\mathrm{T}}$ & $\mathrm{P}_{\mathrm{T}}$ \\
\hline 7.348 & $\mathrm{P}_{\mathrm{T}}$ & -- \\
\hline 8.13 & $\mathrm{P}_{\mathrm{T}}$ & $\mathrm{P}_{\mathrm{T}}$ \\
\hline 8.766 & $\mathrm{~T}_{\mathrm{T}}$ & -- \\
\hline 8.848 & -- & $\mathrm{P}_{\mathrm{T}}$ \\
\hline 9.406 & $\mathrm{P}_{\mathrm{T}}$ & $\mathrm{P}_{\mathrm{T}}$ \\
\hline 9.968 & -- & $\mathrm{P}_{\mathrm{T}}$ \\
\hline 10.529 & $\mathrm{P}_{\mathrm{T}}$ & $\mathrm{P}_{\mathrm{T}}$ \\
\hline 10.855 & $\mathrm{P}_{\mathrm{T}}$ & -- \\
\hline
\end{tabular}

There were a total of nine FERRA rakes consisting of four types. Each type typically consisted of an equal number of total pressure and total temperature probes arranged in alternating fashion, as shown in Table 3, except that rake $\mathrm{D}$ lacked a total temperature probe nearest the base of the rake due to space limitations.

Table 3. Arrangement of $P_{T}$ and $T_{T}$ probes on the FERRA rakes. 


\begin{tabular}{|c|c|c|c|c|c|}
\hline \multirow{2}{*}{ Radius, in } & \multicolumn{2}{|c|}{ Tube Type } & \multicolumn{2}{|c|}{ Tube Type } \\
\cline { 2 - 3 } \cline { 5 - 6 } & $\begin{array}{c}\text { Rake C } \\
\text { (qty. 3) }\end{array}$ & $\begin{array}{c}\text { Rake D } \\
\text { (qty. 2) }\end{array}$ & Radius, in & $\begin{array}{c}\text { Rake E } \\
\text { (qty. 2) }\end{array}$ & $\begin{array}{c}\text { Rake F } \\
\text { (qty. 2) }\end{array}$ \\
\hline 5.530 & $\mathrm{~T}_{\mathrm{T}}$ & $\mathrm{P}_{\mathrm{T}}$ & 5.220 & $\mathrm{~T}_{\mathrm{T}}$ & $\mathrm{P}_{\mathrm{T}}$ \\
\hline 6.151 & $\mathrm{P}_{\mathrm{T}}$ & $\mathrm{T}_{\mathrm{T}}$ & 5.840 & $\mathrm{P}_{\mathrm{T}}$ & $\mathrm{T}_{\mathrm{T}}$ \\
\hline 6.771 & $\mathrm{~T}_{\mathrm{T}}$ & $\mathrm{P}_{\mathrm{T}}$ & 6.462 & $\mathrm{~T}_{\mathrm{T}}$ & $\mathrm{P}_{\mathrm{T}}$ \\
\hline 7.384 & $\mathrm{P}_{\mathrm{T}}$ & $\mathrm{T}_{\mathrm{T}}$ & 7.079 & $\mathrm{P}_{\mathrm{T}}$ & $\mathrm{T}_{\mathrm{T}}$ \\
\hline 7.981 & $\mathrm{~T}_{\mathrm{T}}$ & $\mathrm{P}_{\mathrm{T}}$ & 7.685 & $\mathrm{~T}_{\mathrm{T}}$ & $\mathrm{P}_{\mathrm{T}}$ \\
\hline 8.554 & $\mathrm{P}_{\mathrm{T}}$ & $\mathrm{T}_{\mathrm{T}}$ & 8.271 & $\mathrm{P}_{\mathrm{T}}$ & $\mathrm{T}_{\mathrm{T}}$ \\
\hline 9.093 & $\mathrm{~T}_{\mathrm{T}}$ & $\mathrm{P}_{\mathrm{T}}$ & 8.828 & $\mathrm{~T}_{\mathrm{T}}$ & $\mathrm{P}_{\mathrm{T}}$ \\
\hline 9.593 & $\mathrm{P}_{\mathrm{T}}$ & $\mathrm{T}_{\mathrm{T}}$ & 9.349 & $\mathrm{P}_{\mathrm{T}}$ & $\mathrm{T}_{\mathrm{T}}$ \\
\hline 10.049 & $\mathrm{~T}_{\mathrm{T}}$ & $\mathrm{P}_{\mathrm{T}}$ & 9.827 & $\mathrm{~T}_{\mathrm{T}}$ & $\mathrm{P}_{\mathrm{T}}$ \\
\hline 10.457 & $\mathrm{P}_{\mathrm{T}}$ & $\mathrm{T}_{\mathrm{T}}$ & 10.259 & $\mathrm{P}_{\mathrm{T}}$ & $\mathrm{T}_{\mathrm{T}}$ \\
\hline 10.816 & $\mathrm{~T}_{\mathrm{T}}$ & $\mathrm{P}_{\mathrm{T}}$ & 10.643 & $\mathrm{~T}_{\mathrm{T}}$ & $\mathrm{P}_{\mathrm{T}}$ \\
\hline 11.050 & $\mathrm{P}_{\mathrm{T}}$ & -- & 10.978 & $\mathrm{P}_{\mathrm{T}}$ & $\mathrm{T}_{\mathrm{T}}$ \\
\hline
\end{tabular}

For both the AIPRRA and the FERRA, static pressure ports were located at the base of each rake at the probe measurement plane on the casing surface of the rotating rake spool. For the FERRA, static pressure ports were also located along the hub surface at the probe measurement plane. For the AIPRRA, there were no static-pressure ports on the hub.

\section{Integrated Total Pressure and Total Temperature}

Several data processing techniques were used to analyze the data from the conditions where surveys were taken. Comparisons between the results from the sparse data handling techniques and the full survey data will be used to recommend which of the techniques to use for the analysis of the full set of snapshot data.

\section{Methods}

To mitigate any differences from changing test conditions, computations were completed using data normalized by $\left(\mathrm{P}_{\mathrm{T}}\right.$ and $\left.\mathrm{T}_{\mathrm{T}}\right)$ or corrected to $\left(\mathrm{W}_{\mathrm{C}}\right)$ freestream conditions. For the purpose of calculating fan performance parameters, mass-flow-averaged $\mathrm{P}_{\mathrm{T}}$ and $\mathrm{T}_{\mathrm{T}}$ were determined for the AIP and FE. The methods used to calculate elemental mass flows will be discussed in a subsequent section. Unenhanced snapshots were extracted from surveys by selecting a subset of the survey data where the rake array was positioned at $0^{\circ}$. By extracting a snapshot from within the survey itself the test conditions were, to the greatest extent possible, identical for a paired survey and snapshot.

\section{a. Calculating Integrated Parameters Using Unenhanced Snapshot Data}

The most basic approach to processing a snapshot is to process the unenhanced snapshot data directly using the same methods used for survey data. Briefly, for each probe an area was defined such that its value was ascribed to a region that covers half of the area between the probe and its neighbors in both the radial and circumferential directions. Static pressures - at the case and two radial locations for the AIP and at the hub and case for the FE-were used to calculate velocity at each probe. Note that the density of probes was such that for surveys the boundary layer was apparent in the total pressures. Total pressure at the walls was assumed equal to static pressure. A mass flow was calculated for each area, which was used to mass-flow-average the total pressure at the AIP and total pressure and total temperature at the FERRA. Because there were so few temperature measurements at the AIP and the measurements indicated that the temperature was actually not uniform across the plane (contrary to what was assumed going into the test), additional processing ${ }^{11}$ was necessary to obtain the average total temperature. 


\section{b. Development of Enhanced Snapshots Using Standard Interpolations}

The unenhanced snapshot data were interpolated onto a regular $(\mathrm{r}, \theta)$ grid of $(14,72)$ points for the AIPRRA and $(26,72)$ points for the FERRA. These grids were selected such that the enhanced snapshots would have the same data resolution as surveys. Because the grids of unenhanced snapshot data points were not regular, separate interpolation steps were necessary in the following sequence: 1) radial interpolation at the rake circumferential locations, 2) circumferential interpolation between existing rake end-points to fill in missing end-points near the hub (not needed for FERRA $\mathrm{P}_{\mathrm{T}}$ ), and 3) circumferential interpolation to fill in circumferential locations between the rakes. An illustration of this sequence is shown in Fig. 7. In each subfigure, the points where values are known are shown in black and the values to be calculated during that step are shown in red. All standard interpolation calculations were performed in MATLAB 2017a using the built-in interpolation functions.

Four standard interpolation techniques were used to enhance the snapshot data. Bilinear interpolation used linear interpolations in both directions. Linear/Cubic Spline (LCS) used linear interpolation in the radial direction, then cubic spline ${ }^{12}$ interpolation in the circumferential direction. Piecewise Cubic Hermite Interpolating Polynomial (PCHIP) used the PCHIP ${ }^{13}$ method in both directions. The PCHIP routine uses a constrained cubic spline which eliminates overshoot. Bidirectional Cubic Spline (BiCS) used the cubic spline method in both directions.

These four standard interpolation techniques were used to calculate the total pressure at the AIP and the total pressure and total temperature at the FE. The total temperature at the AIP was not enhanced in the same manner. Instead, the approach used to fill in AIP total temperature data for surveys ${ }^{11}$ was applied. That approach used the total pressures at the AIP to guide the total temperature reconstruction in the high distortion region, yielding a unique total temperature field for each enhancement method.

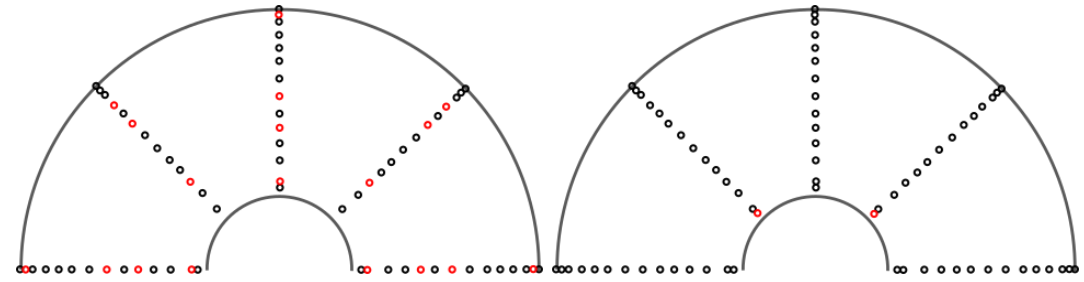

a) b)

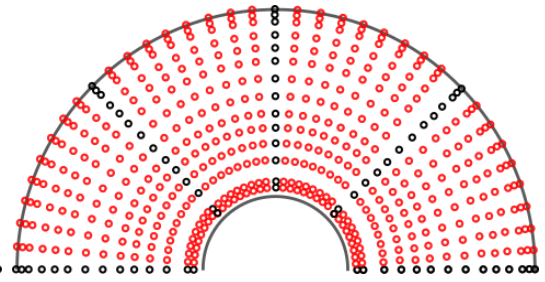

c)

Figure 7. Illustration of the interpolation steps for the standard interpolation methods. Black symbols indicate data available at the beginning of the the step, and red symbols indicate locations at which interpolated values are calculated during that step. a) Step 1: radial interpolation at the rake circumferential locations b) Step 2: circumferential interpolation near the hub c) Step 3: circumferential interpolation between the rakes.

\section{c. Development of Enhanced Snapshots Using Guided Interpolations}

The Guided Interpolation (GI) technique seeks to use information from a survey as a template to enhance a snapshot. It relies on the fact that the $\mathrm{P}_{\mathrm{T}}$ and $\mathrm{T}_{\mathrm{T}}$ fields at the AIP and FE are similar across the survey range. The approach relies on calculating a warping function to transform survey data, resulting in a set of points at survey density that passes through all points in the unenhanced snapshot data while retaining the shape of the survey data between snapshot data points.

A simplified one-dimensional example of the GI approach is shown in Fig. 8. In this example, the unenhanced snapshot field is represented by $f_{a}=1+0.3 \sin (\theta / 2)$ while the template survey field is represented by $f_{b}=0.5+0.1 \sin (10 \theta) \sin (\theta / 2)$, both of which are shown in the upper left subfigure. Shown in the upper right subfigure, function $f_{c}$ is created by interpolating the survey function $f_{b}$ to the coordinates of snapshot function $f_{a}$ resulting in two functions with common coordinates, so that function $f_{d}$ can be created by dividing $f_{a}$ by $f_{c}$. In this way, function $f_{d}$ becomes the warping factor for the template function, $f_{b}$. Shown in the lower left subfigure, function $f_{e}$ is created by interpolating warping function $f_{d}$ to the coordinates of $f_{b}$. This results in a warping function $f_{e}$ that has common coordinates with the template $f_{b}$, which allows the template to be applied to the snapshot data, $f_{a}$ The enhanced snapshot function $f_{f}$ is created by multiplying $f_{b}$ by $f_{e}$. In the lower right subfigure, $f_{a}$ and $f_{f}$ are plotted together, showing that function $f_{f}$ passes through all of the points in snapshot $f_{a}$ while taking on the shape of template $f_{b}$ between the existing points. In this somewhat contrived example, the two functions are shaped quite differently for illustrative purposes. 

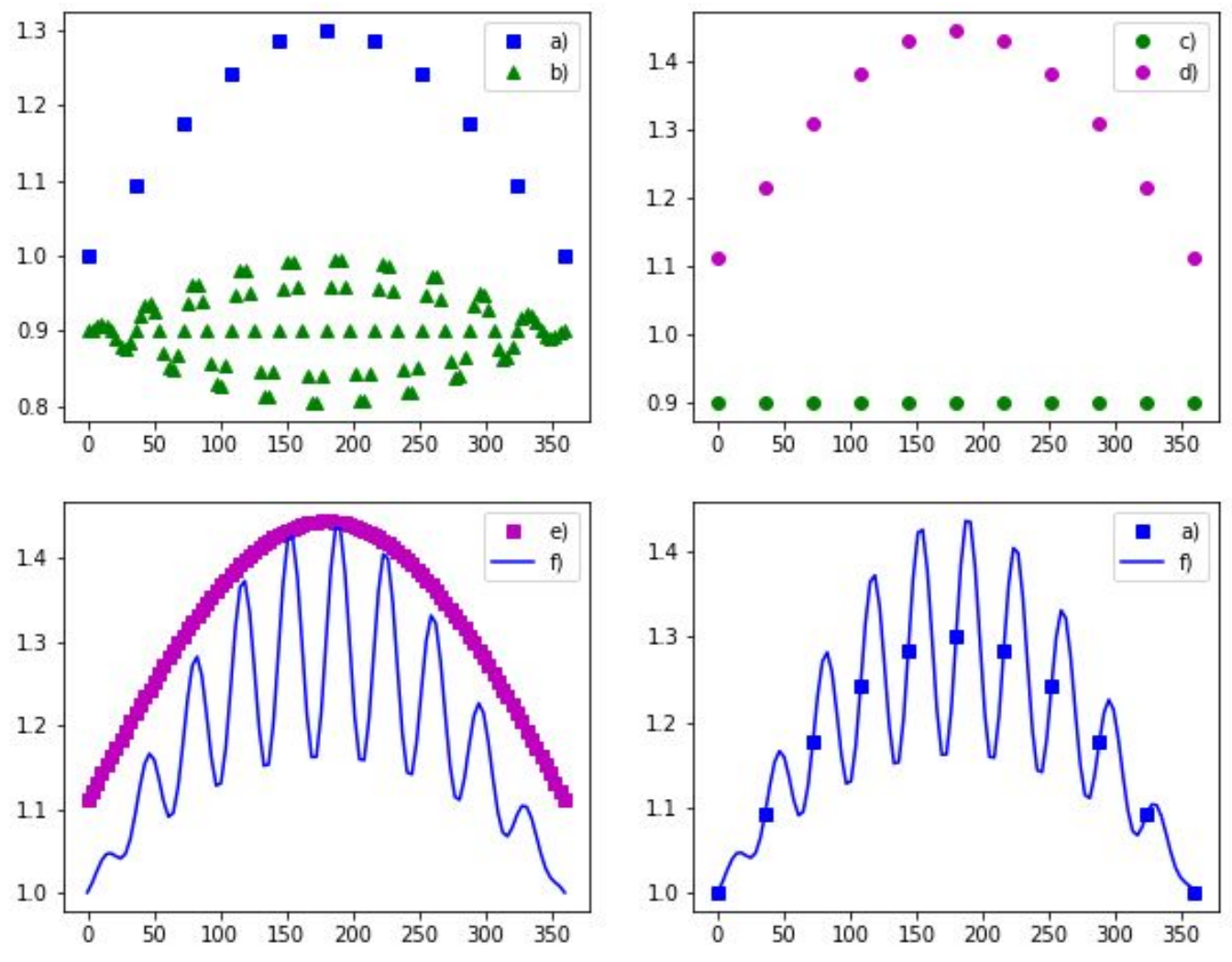

Figure 8. Illustration of 1D guided interpolation technique.

Figure 9 illustrates the process of expanding the guided interpolation approach to two dimensions. Subfigure (a) represents the unenhanced snapshot data measured at an operating condition of interest. Subfigure (b) represents the template survey data, typically measured at a different operating condition. Arrows in the figure indicate the flow of coordinates $(\mathrm{r}, \theta)$ and functional values (f) from one step to the next. The functional values (normalized total pressure or normalized total temperature) from the survey are interpolated onto the locations of the snapshot measurements, as shown in subfigure (c). The functional values from the snapshot are divided by the functional values in subfigure (c) to create a warping factor, shown in subfigure (d). The warping factors in subfigure $d$ are interpolated to the locations of the survey measurements, as shown in subfigure (e). Finally, the functional values for the survey are multiplied by the warping factor in subfigure (e) to produce the enhanced snapshot dataset, shown in subfigure (f). GI enhancement calculations were performed using Python scripts. In all cases, linear interpolations using functions from the scipy.interpolate library were used in the GI method. Specifically, the "interp2D" function was used to create interpolated survey $f_{c}$, and the "griddata" function was used to create warping function $f_{e}$. Higher order interpolations were investigated but not found to improve the results.

One consideration when using the guided interpolation method is the selection of a template from the available surveys. Intuitively it seems that a snapshot enhanced using a survey with significantly different operating conditions would produce less accurate results than using a survey with similar operating conditions. To examine this, two types of guided interpolations were performed. In the first, named "GI ADP", the ADP survey was used as the template for the interpolation throughout. In the second method, named "GI Near", the nearest survey in the direction of the ADP was used as the template for the interpolation. The result of this definition is that for five points, namely the ADP and the four points nearest the ADP, the template point is the ADP.

Guided interpolation was used to calculate the total pressure at the AIP and the total pressure and total temperature at the FE. Because there were only 8 total temperature measurements at the AIP, the total temperature there was not enhanced in the same manner. 


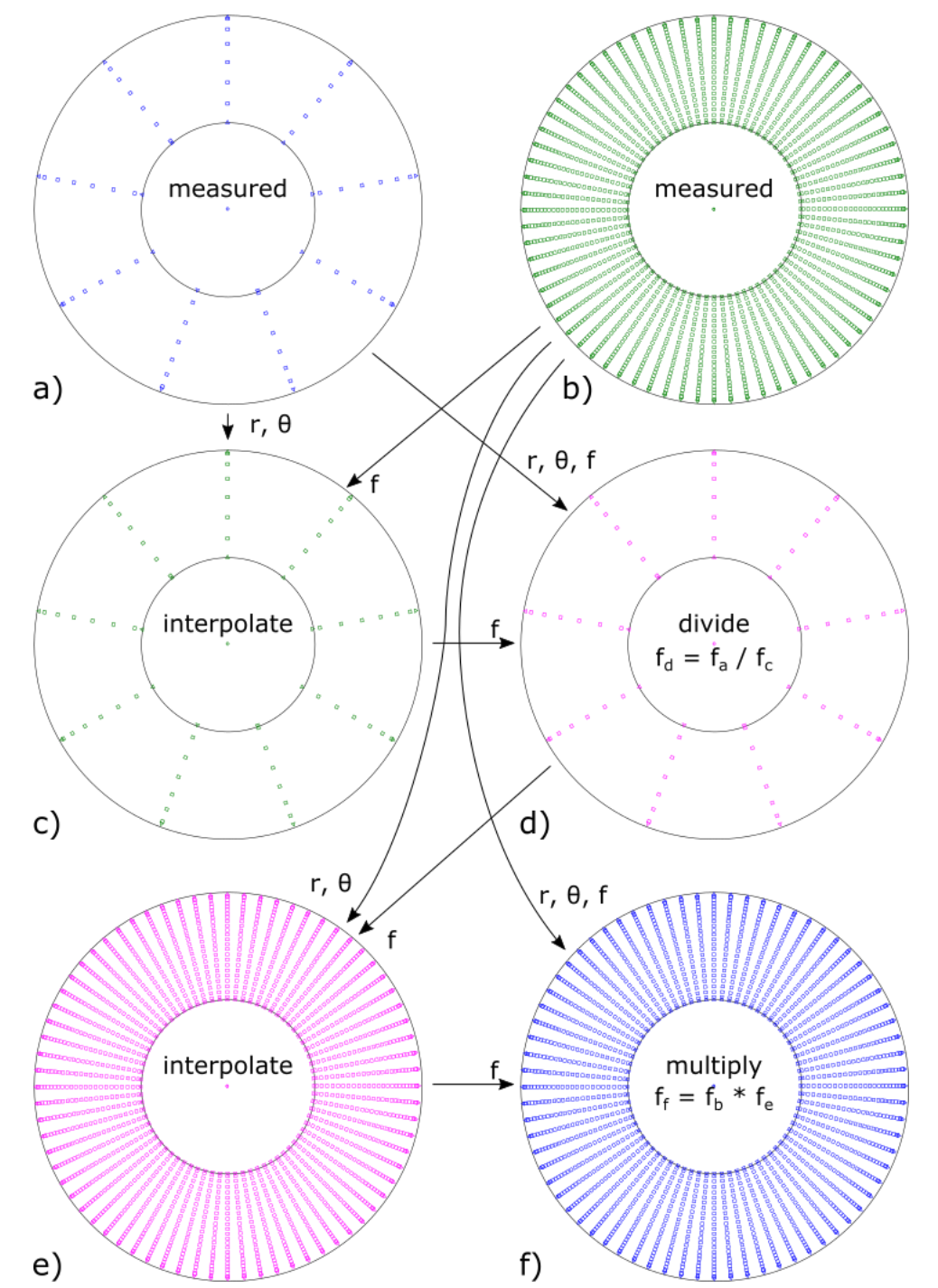

Figure 9. Illustration of the guided interpolation technique in two dimensions.

\section{Results and Discussion}

For the purpose of this evaluation, the error of a snapshot method is the difference between the snapshot result and the result from the full survey from which that snapshot was taken. In this section, plots are shown of the resulting error for each of the snapshot processing methods. Additionally, contour plots of the total pressures and total temperatures are shown for each method. Finally comparisons of the trend lines of the predicted values from each method versus the survey values are used to consider the accuracy and precision of the methods.

\section{a. Integrated Pressure and Temperature from Snapshots}

The error in the predicted AIP total pressure for the unenhanced snapshots and each of the four standard interpolation methods is shown in Fig. 10 plotted against the AIP total pressure calculated from the survey. The heavy line highlights zero error relative to the survey data. In general, the unenhanced snapshot AIP total pressure provides reasonable results, with a mean near zero and errors no larger than $0.01 \mathrm{psia}$. It is important to note that this error is relative to a survey value which itself has an uncertainty of up to 0.051 PSIA (depending on operating condition) as reported previously by Wolter ${ }^{8}$.

Total analytical error ${ }^{14}$ (TAE) was used for this study to serve as a single worst-case measure of error because it combines bias and random errors. The total analytical errors of the snapshot-based methods includes the uncertainty for the survey, so these values will automatically be greater than those for the surveys. Based on the measured errors 
and the survey uncertainty, it is estimated that for any unenhanced snapshot processed in this manner, the TAE in the AIP total pressure would be 0.051 PSIA.

The PCHIP and LCS methods perform similarly and are the best of the four enhancement methods for AIP total pressure, and the BiCS method performs particularly poorly here in comparison. However, as the magnitude of the errors in AIP total pressure for the unenhanced snapshot were also less than 0.01, nothing is gained from the application of the standard interpolation techniques in terms of AIP total pressure.

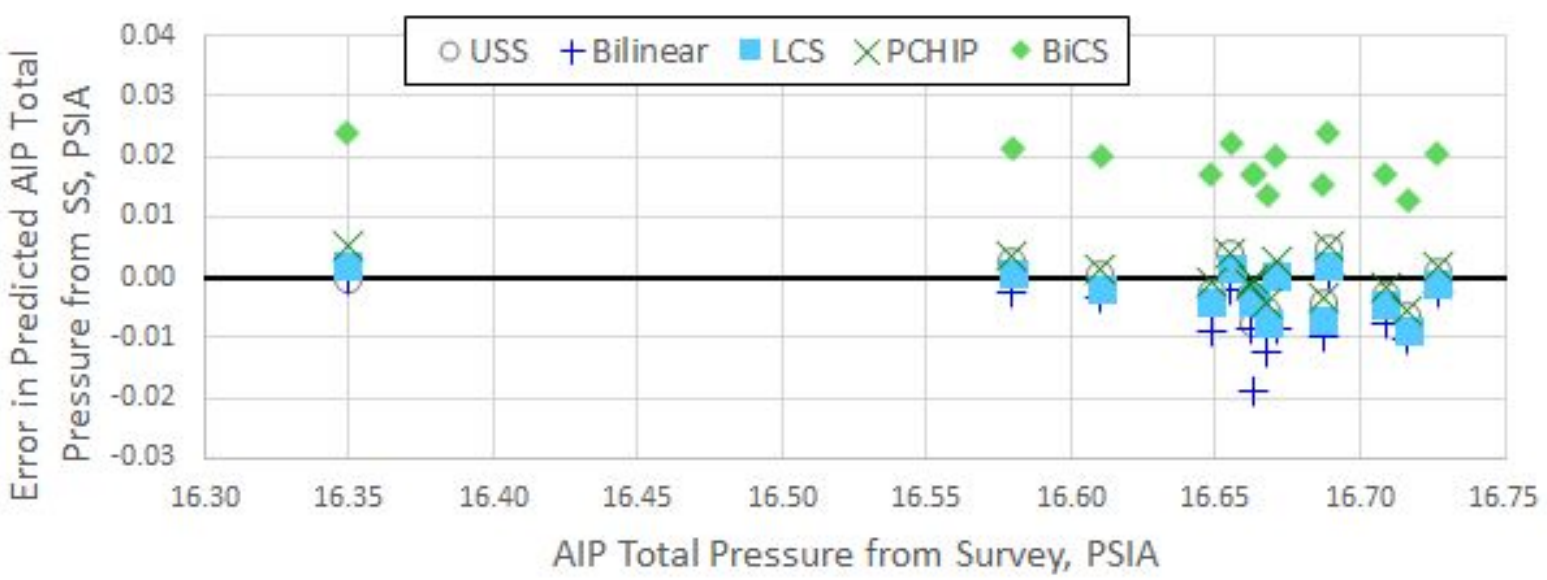

Figure 10. Error in predicted AIP total pressure for unenhanced and enhanced snapshots.

The error in the predicted AIP total temperature for the unenhanced snapshots and each of the four standard interpolation methods is plotted against the AIP total temperature from the survey and shown in Fig. 11. In this case, a negative bias can be seen between the results from all methods and the survey. For the unenhanced snapshots the magnitude of the maximum error was $0.175 \mathrm{R}$. Based on the measured errors and the survey uncertainty, it is estimated that the TAE for the AIP total temperature for the unenhanced snapshots would be $0.60 \mathrm{R}$. For the four standard interpolation methods there is little change in the result compared to the unenhanced snapshot.

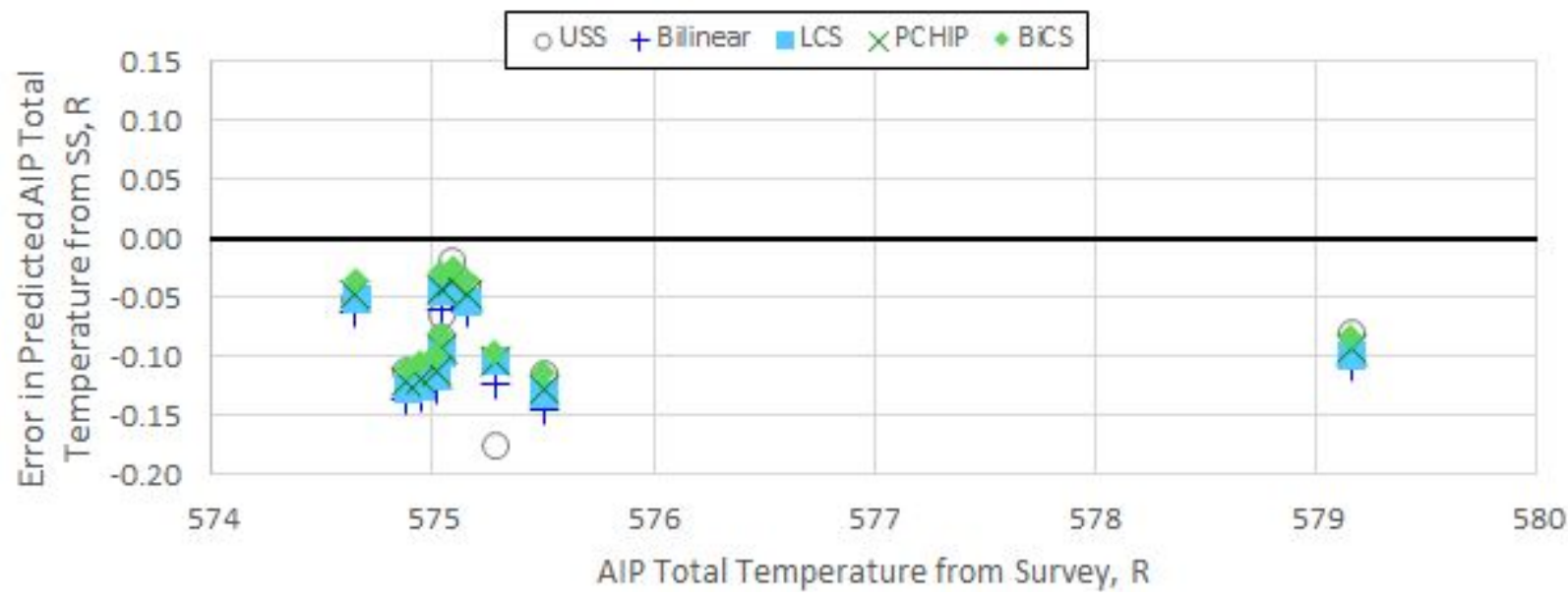

Figure 11. Error in predicted AIP total temperature for unenhanced and enhanced snapshots.

The error in the predicted FE total pressure for the unenhanced snapshots and each of the four standard interpolation methods is shown in Fig. 12 plotted against the FE total pressure from the survey. The errors at the FE suffer from noticeable bias errors relative to the survey for all methods but the PCHIP. This led to errors in the total pressure calculated by the unenhanced snapshot method that were an order of magnitude larger at the FE than at the AIP. Based on the measured errors and the survey uncertainty, it is estimated that for any unenhanced snapshot processed in this manner, the TAE for the FE total pressure would be 0.211 PSIA. The PCHIP method is the best of 
the standard interpolation methods for FE total pressure. The biCS method performs slightly worse in comparison, particularly at the lower pressures. The bilinear and LCS methods perform similarly to each other and are the worst of the standard interpolation methods. All four standard interpolation methods perform better than the unenhanced snapshot method.

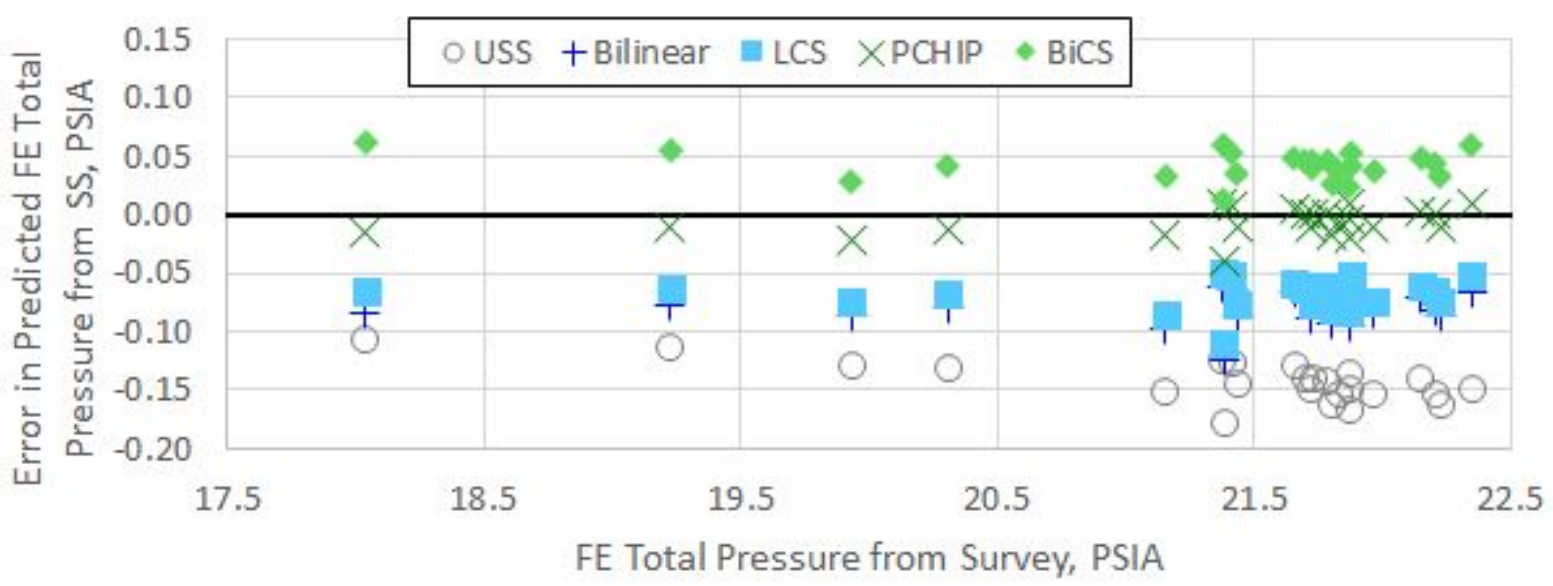

Figure 12. Error in predicted FE total pressure for unenhanced and enhanced snapshots.

The error in the predicted FE total temperature for the unenhanced snapshots and each of the four standard interpolation methods is shown in Fig. 13 plotted against the FE total temperature from the survey. As for the FE total pressure, the unenhanced snapshot method exhibits a bias error, particularly at higher temperatures. Based on the measured errors and the survey uncertainty, it is estimated that for any unenhanced snapshot processed in this manner, the TAE for the FE total pressure would be $2.33 \mathrm{R}$. The large TAE for the FE total temperature is of particular concern for low pressure ratio fans, such as the one tested here, and is expected to lead to large errors in the calculation of efficiency for this approach.

All four standard interpolation methods outperform the unenhanced snapshot in terms of the error in the predicted FE total temperature. The LCS and PCHIP methods perform similarly to each other and are the best of the four methods. The bilinear and BiCS methods perform worse by comparison.

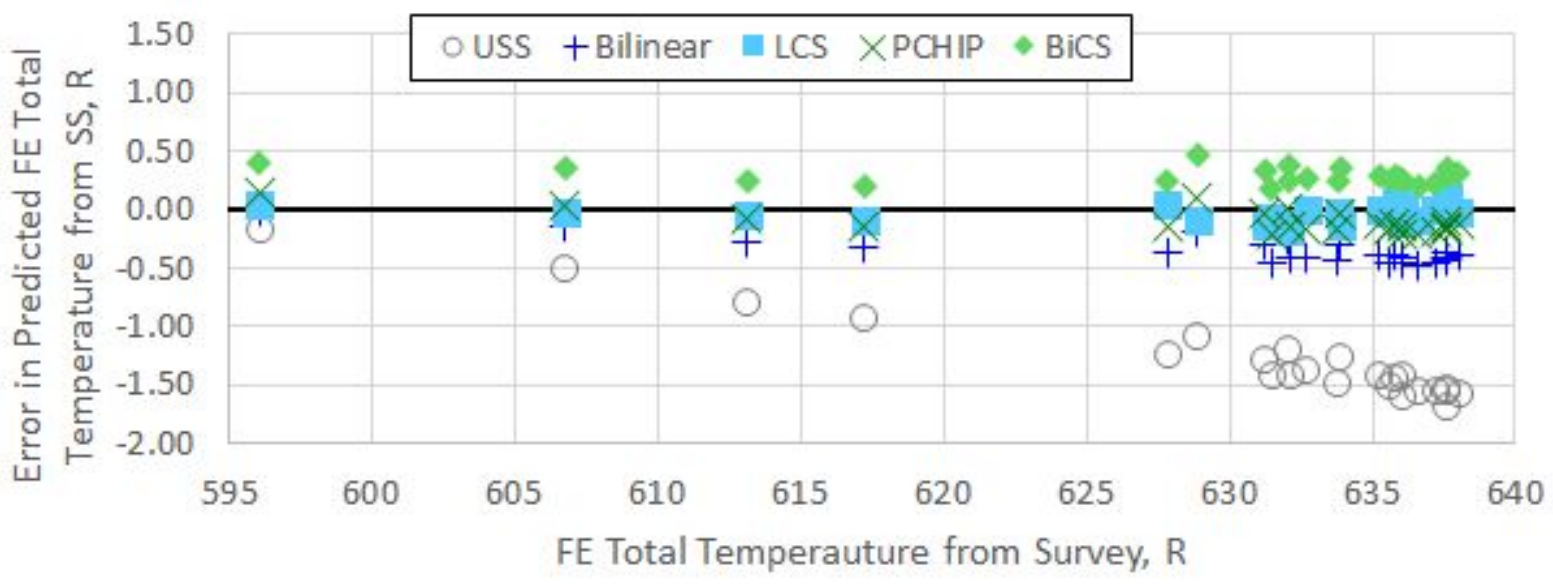

Figure 13. Error in predicted FE total temperature for unenhanced and enhanced snapshots.

\section{b. Integrated Pressure and Temperature from Enhanced Snapshots Using Guided Interpolations}

The error in the predicted AIP total pressure for the guided interpolation methods is shown in Fig. 14 plotted against the AIP total pressure calculated from the survey. Both methods perform well. However, as with the standard interpolation methods, nothing is gained from the application of the guided interpolation techniques in terms of AIP total pressure. Similarly, the error in the predicted AIP total temperature for each of the guided 
interpolation methods, shown in Fig. 15, indicates that there is little change in the result compared to processing the unenhanced snapshot directly.

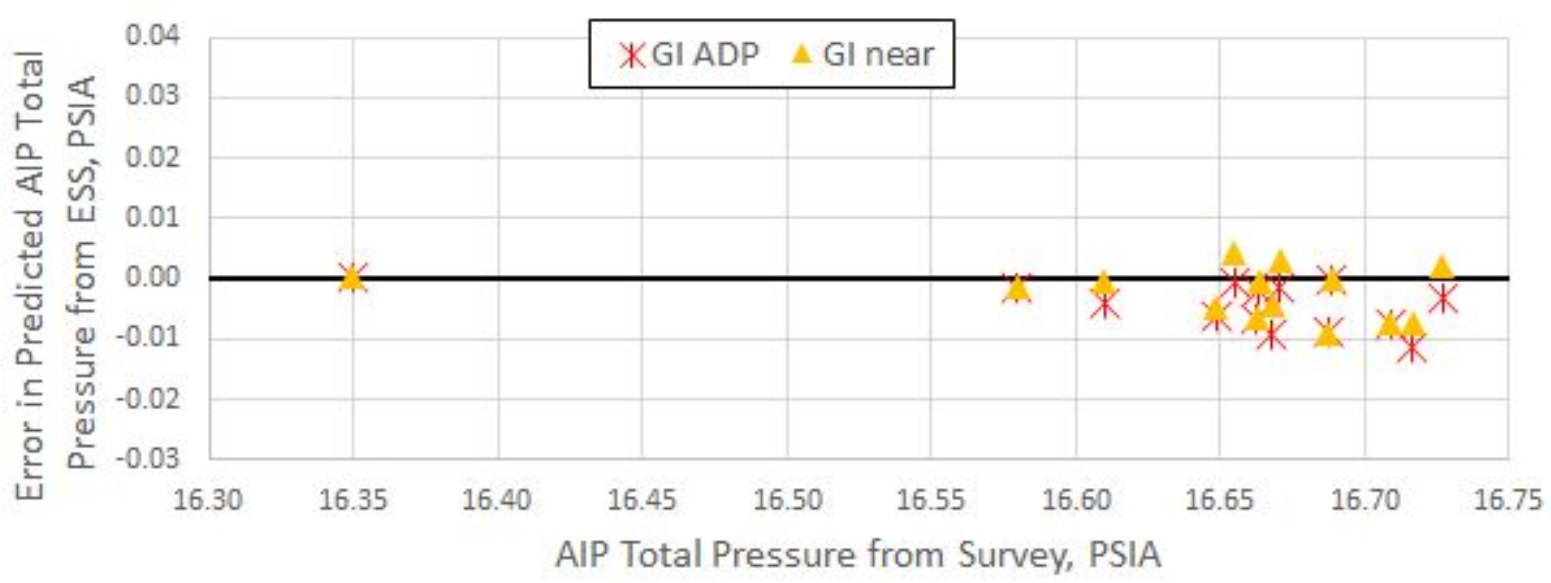

Figure 14. Error in predicted AIP total pressure from the guided interpolation ESSs.

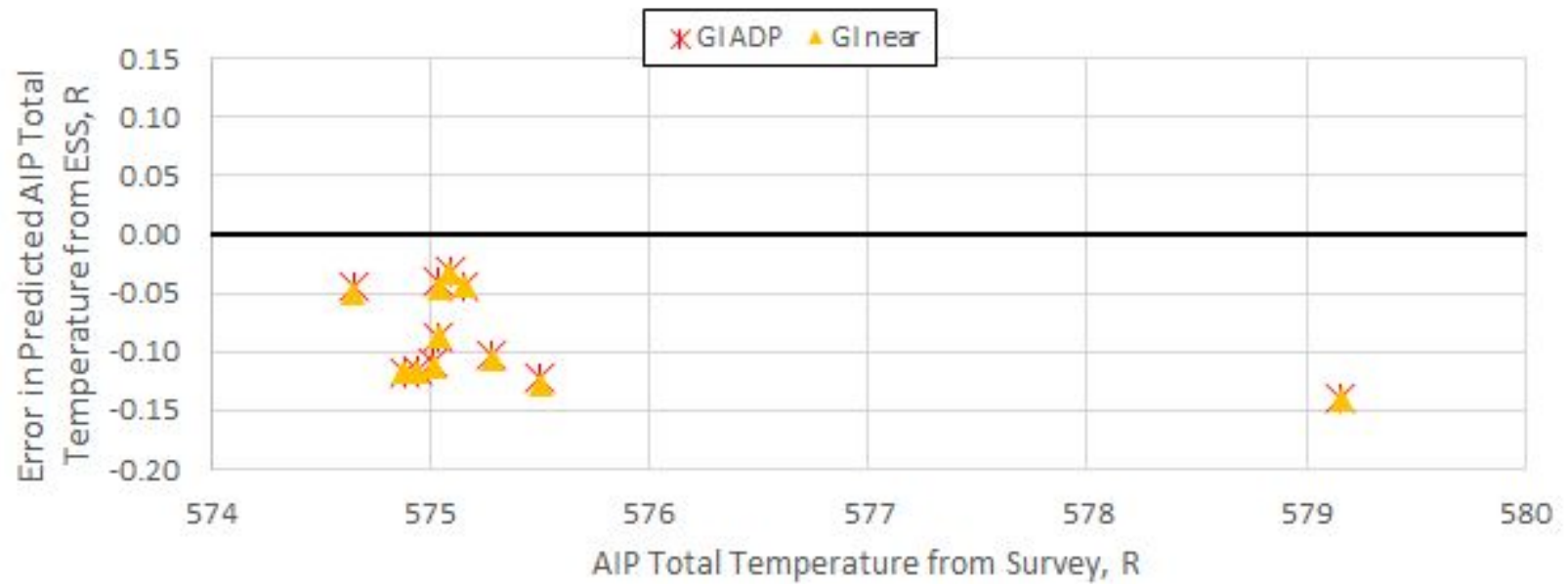

Figure 15. Error in predicted AIP total temperature from the guided interpolation ESSs.

The error in the predicted FE total pressure for the guided interpolation methods is shown in Fig. 16 plotted against the FE total pressure calculated from the survey. Both guided interpolation methods perform better than the unenhanced snapshot method, and the GI Near method slightly outperforms PCHIP, the best of the standard interpolation methods.

For the error in the predicted FE total temperature, shown in Fig. 17, The GI Near method performs better than the GI ADP method. Both methods are much better than the unenhanced snapshot. The GI Near method is comparable to the LCS method, the best of the standard interpolation methods. 


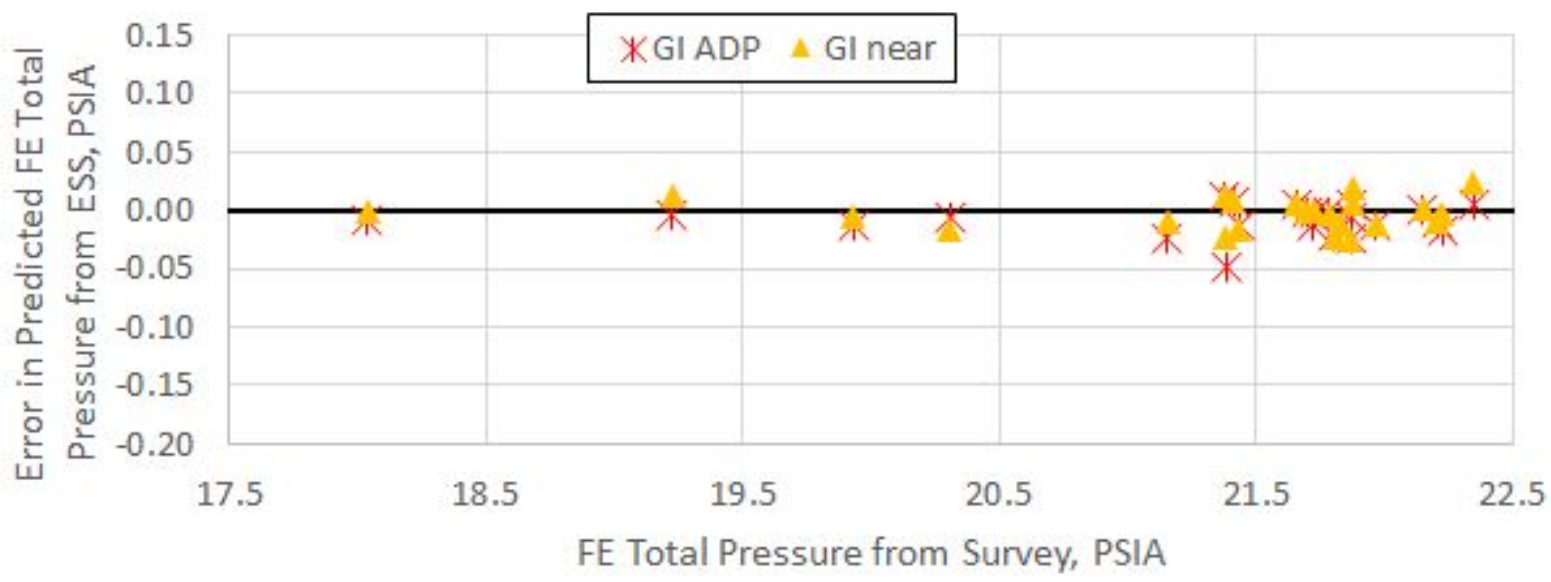

Figure 16. Error in predicted FE total pressure from the guided interpolation ESSs.

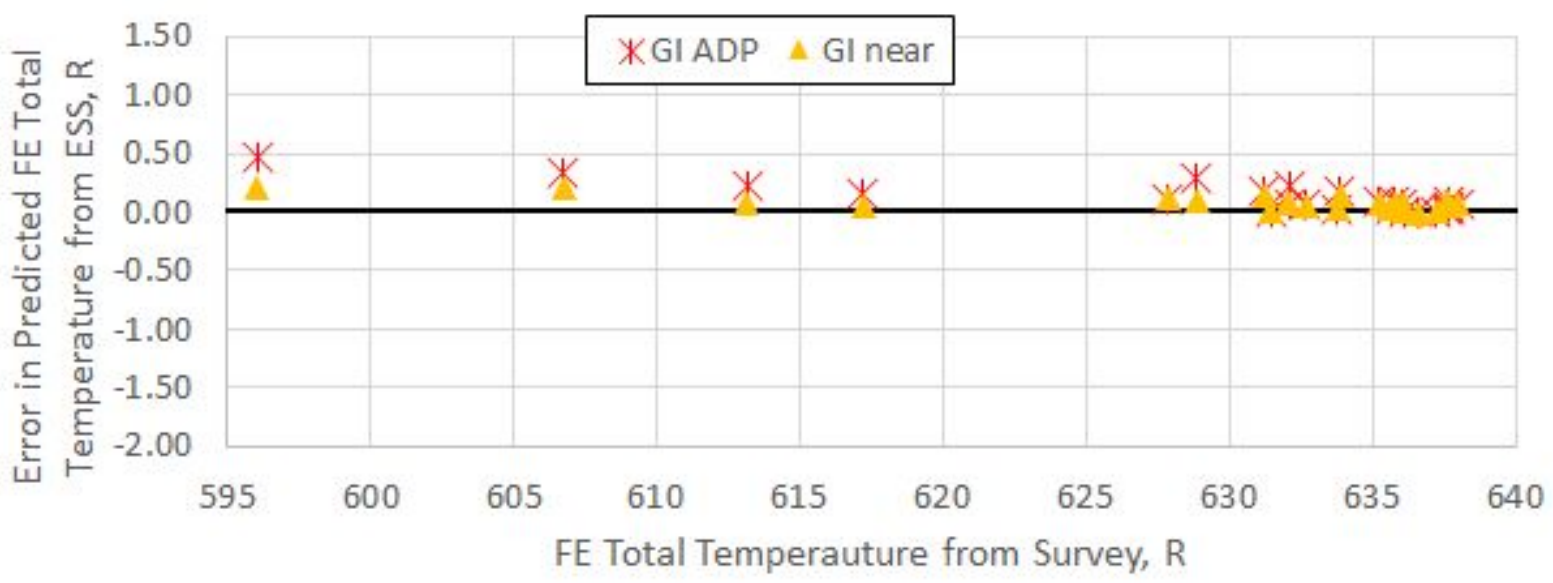

Figure 17. Error in predicted FE total temperature from the guided interpolation ESSs.

Figures 18 and 19 show the same data as Fig. 17; however, it has been divided to show only the points along the constant-exit-corrected-flow line (Fig. 18) and the 100\% speed line (Fig. 19). It can be seen in Fig. 18 that the error increases as the fan speed decreases. The error increase is greater for the GI ADP, which suggests that the FE total temperature field is changing shape as the fan speed decreases causing the template survey from the ADP to lead to larger errors. Similarly, it can be seen in Fig. 19 that the error increases as the nozzle opens, bringing the fan toward the choke side of the operating map. With the nozzle farther open the errors are larger for GI ADP than for GI Near indicating again that the shape of the FE total temperature field is changing. 


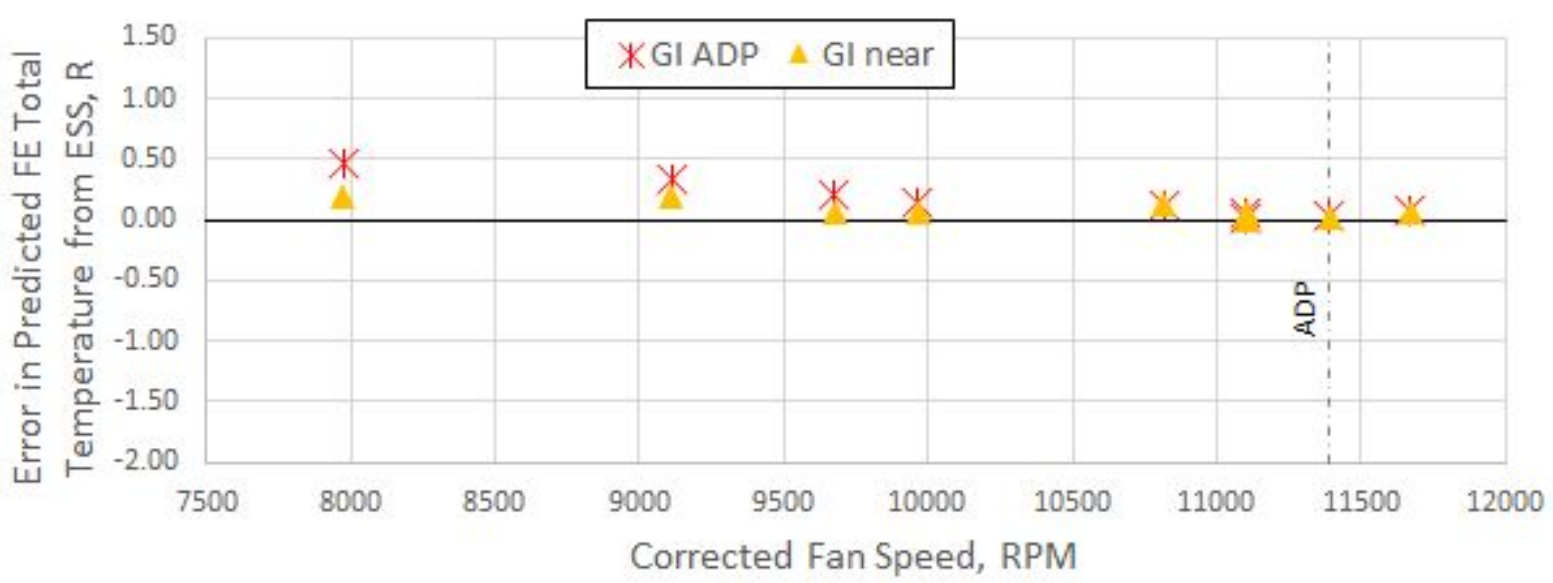

Figure 18. Error in predicted FE total temperature from the guided interpolation ESSs for constant exit-corrected flow.

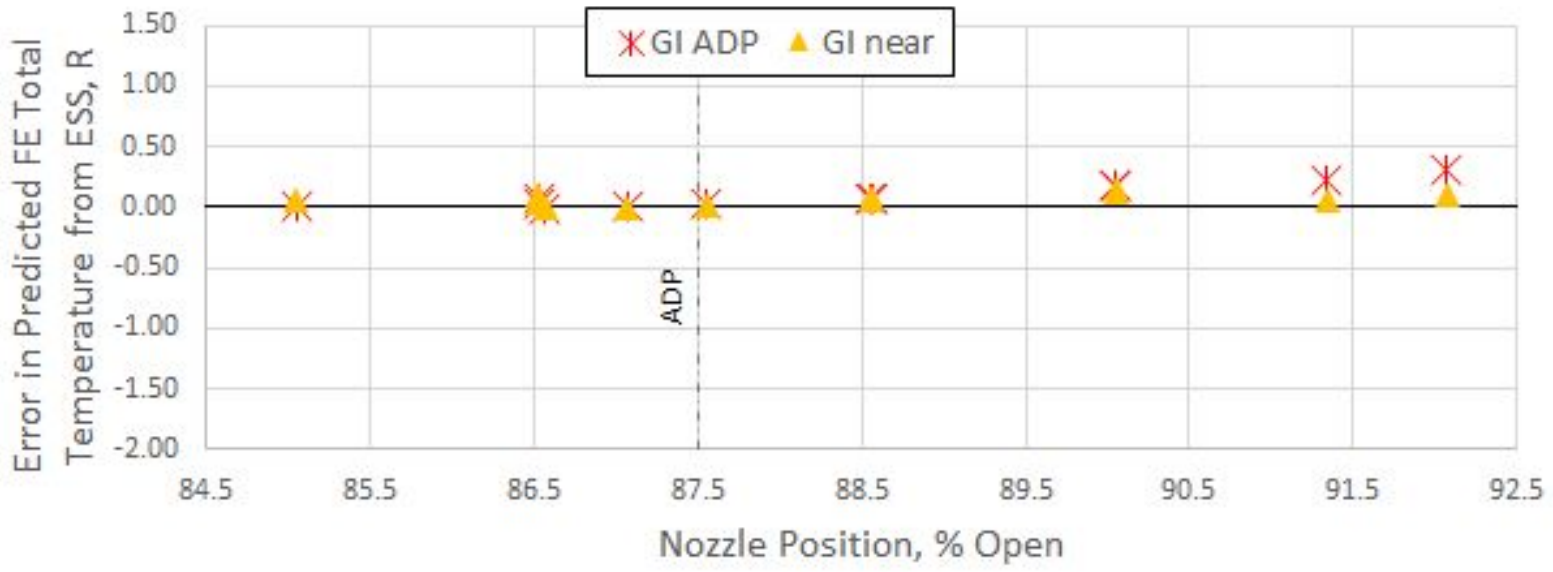

Figure 19. Error in predicted FE total temperature from the guided interpolation ESSs for $100 \%$ speed.

c. Summary of Integrated Pressure and Temperature Results

Figures 20-23 and Table 4 summarize the pressure and temperature results for the various methods. In Fig. 20 contour plots of normalized pressures and temperatures for all methods are shown. Note that GI Near does not appear in the figure, because at the ADP point, GI Near is the same as GI ADP. Of note in these contour plots is that the BiCS method produces artifacts which do not appear in the survey, particularly notable in the $\mathrm{FE}_{\mathrm{T}}$, and $\mathrm{T}_{\mathrm{T}}$, plots. For the FE $\mathrm{P}_{\mathrm{T}}$ ' plots, only the GI methods reproduce the wake structure as captured by the surveys. For the AIP $\mathrm{T}_{\mathrm{T}}$ ' plots the top portion of all the snapshot methods look the same because no enhancement methods were applied there due to extremely sparse data. The bottom portion reflects the use of the $\mathrm{P}_{\mathrm{T}}$ field to fill in the $\mathrm{T}_{\mathrm{T}} \mathrm{s}$, as described previously. 

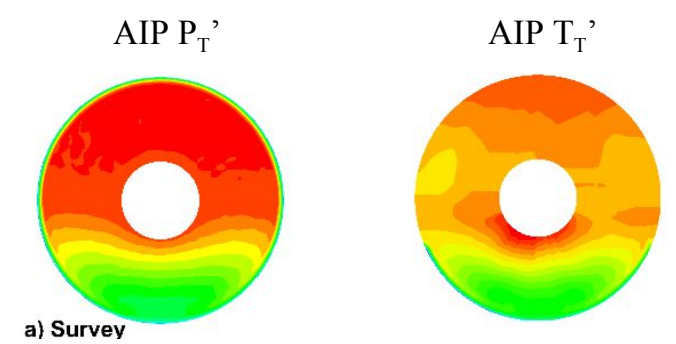

FE $\mathrm{P}_{\mathrm{T}}$ '

$\mathrm{FE} \mathrm{T}_{\mathrm{T}}{ }^{\prime}$
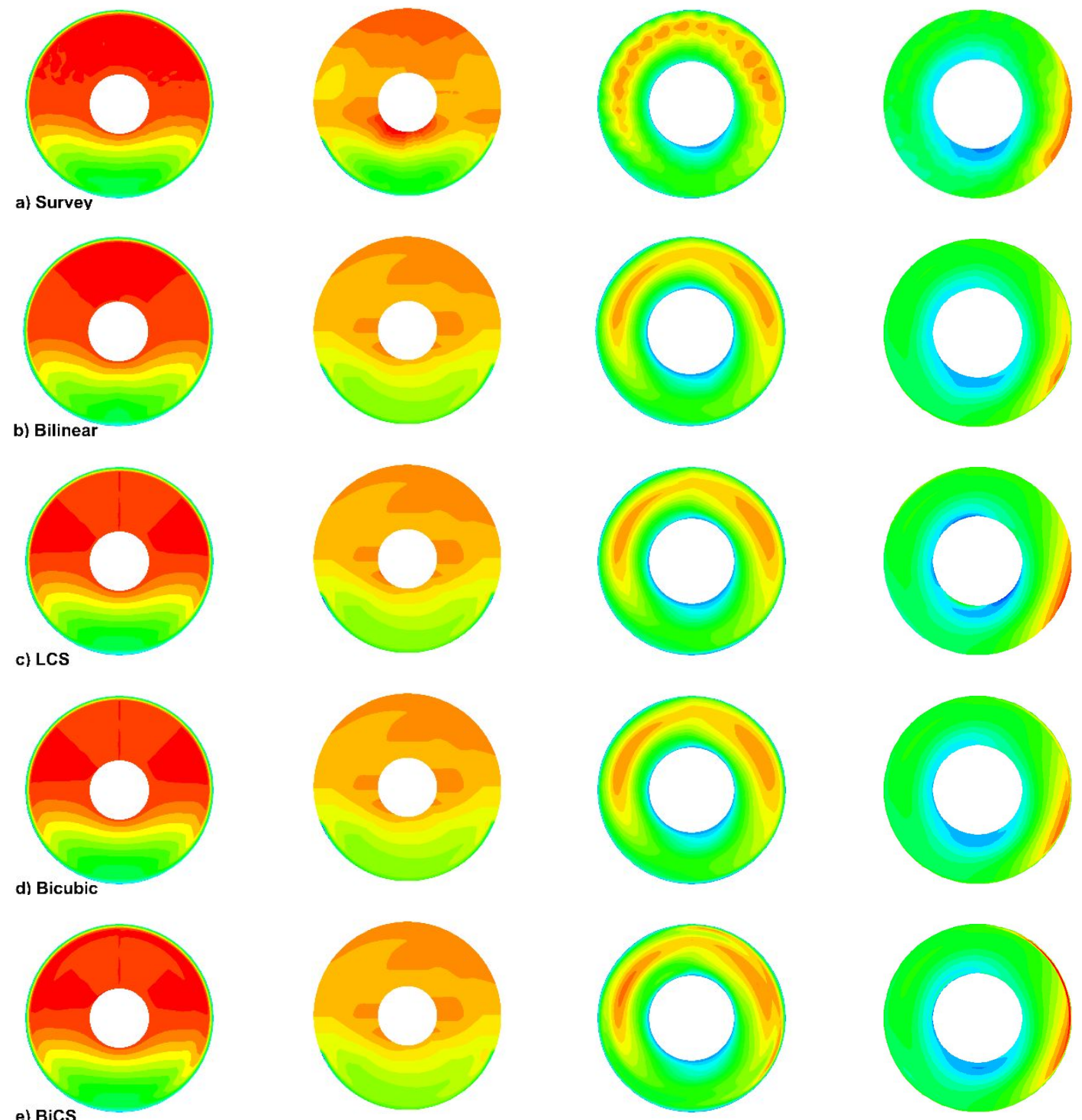

e) BiCs
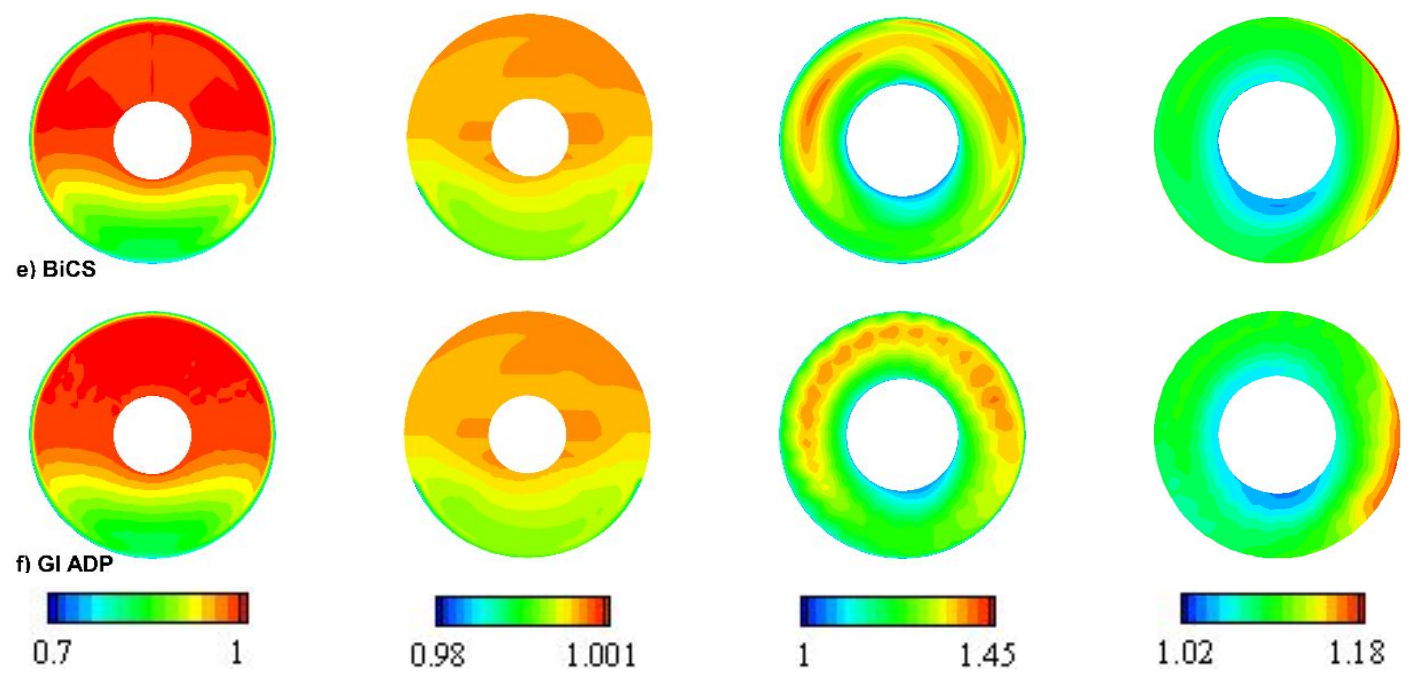

Figure 20. Contour plots of normalized total pressure and total temperature at the AIP and FE planes for each interpolation technique at the ADP

Figure 21 shows a representative plot of AIP total pressure from the USS versus the AIP total pressure from the surveys. A linear trend line with intercepts at the origin is also shown. If a method produced a perfect reproduction of the survey values, a trend line through the dataset would have a slope of one and an intercept at the origin. By forcing the intercept of the trendline to zero, the slope of the curve and the $\mathrm{R}^{2}$ value of the fit represent the accuracy 
and precision, respectively, of the method. A slope less than one indicates that there is a bias in which the method values are consistently lower than the survey values, while a slope greater than one indicates the method values are higher than the survey values. The $\mathrm{R}^{2}$ value then indicates the degree of scatter in the data. While the unenhanced snapshot does not do a perfect job of predicting the survey AIP total pressure, it is difficult to perceive this from the plot.

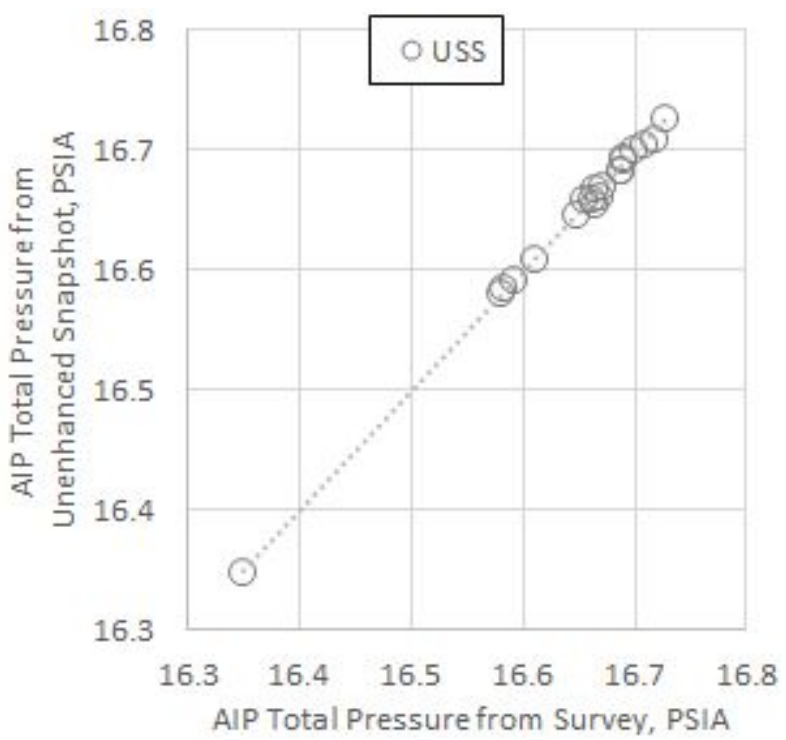

Figure 21. Representative plot showing a trend line calculated from the AIP total pressure from the unenhanced snapshots versus AIP total pressure from the surveys.

Trend lines were calculated for each of the methods with the intercept forced to the origin. The slopes (Fig. 22) and $\mathrm{R}^{2}$ values (Fig. 23) are shown for these trend lines from each of the methods for AIP and FE total pressure and total temperature. It can be seen in Fig. 22 that for the PCHIP, GI ADP, and GI Near methods, the slopes for all four integrated parameters are very close to unity. It can be seen in Fig. 23 that the $\mathrm{R}^{2}$ value is high for all of the methods for the FE parameters. Based on these results a decision was made to carry forward only the PCHIP and GI Near methods, along with the unenhanced snapshots for comparison, to the analysis of the corrected mass flow rate and the efficiency. While the overall values of slope and $\mathrm{R}^{2}$ for the BiCS method may provide a case for its inclusion going forward, the artifacts seen in the contour plots indicate that it's getting the right values for the wrong reasons.

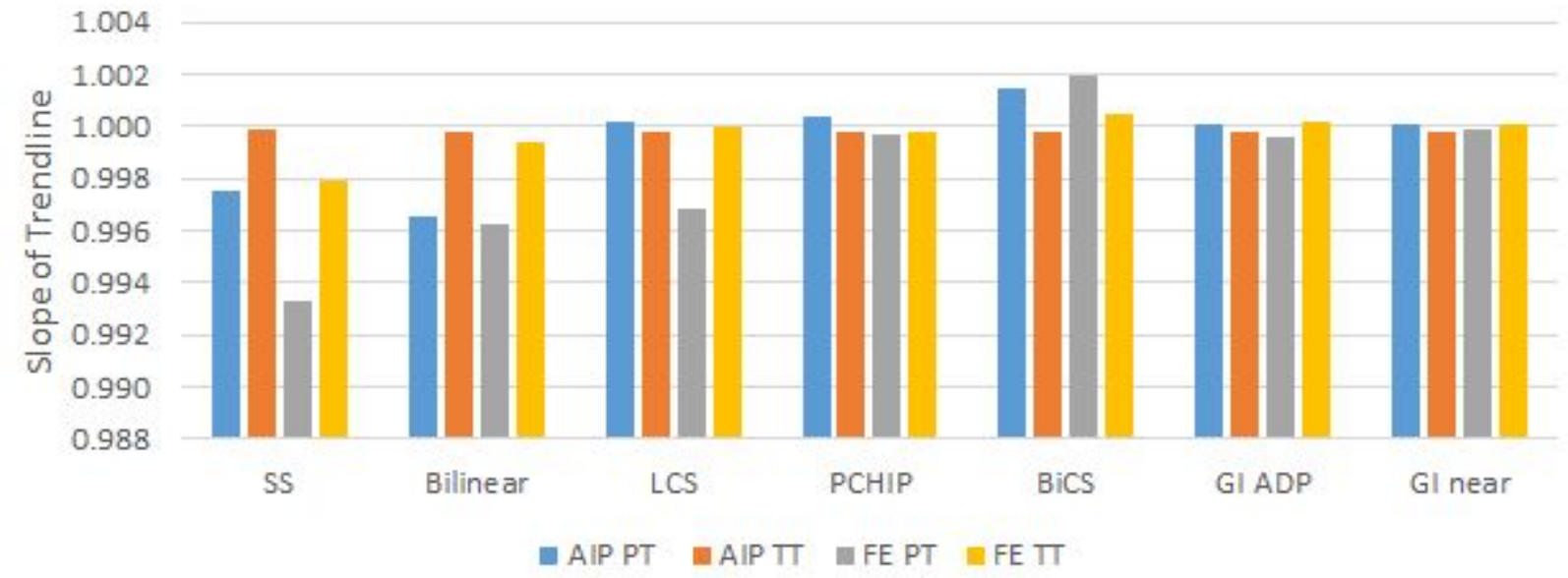

Figure 22. Slope of the trend line of total pressure and total temperature at the AIP and FE for each interpolation method. 


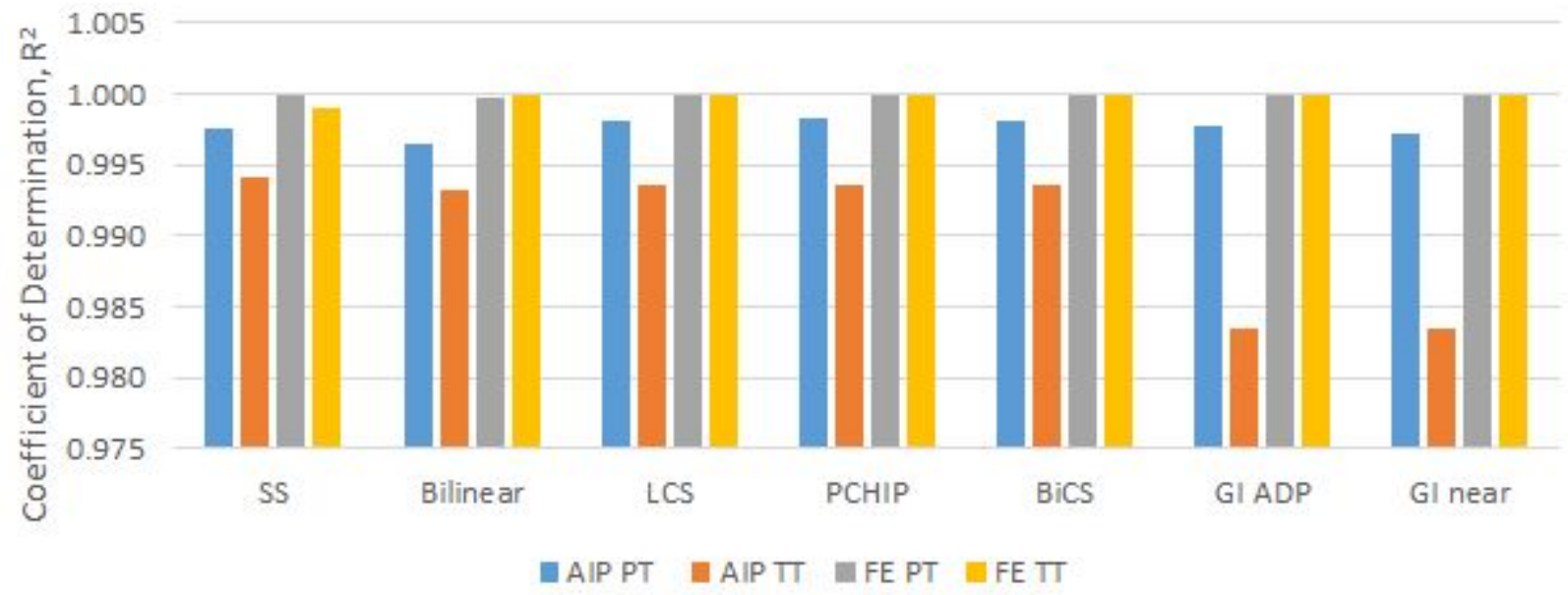

Figure 23. Value of $\mathbf{R}^{2}$ of the trend line of total pressure and total temperature at the AIP and FE for each interpolation method.

Table 4 shows the calculated total analytical errors for integrated total pressure and total temperature predictions for the selected data processing methods at the ADP. These further illustrate that the enhancement methods provide little improvement over the unenhanced snapshot method for the AIP, but that both enhanced snapshot methods provide significant improvements over the unenhanced snapshot method for the FE.

Table 4. Maximum total analytical error for total pressures and total temperatures for selected data processing methods.

\begin{tabular}{|c|c|c|c|c|}
\hline & Survey $^{8}$ & USS & PCHIP & GI Near \\
\hline TAE for AIP $\mathrm{P}_{\mathrm{T}}$ & 0.051 PSIA & 0.051 PSIA & 0.052 PSIA & 0.052 PSIA \\
\hline TAE for AIP $\mathrm{T}_{\mathrm{T}}$ & $0.54 \mathrm{R}$ & $0.60 \mathrm{R}$ & $0.58 \mathrm{R}$ & $0.59 \mathrm{R}$ \\
\hline TAE for FE $\mathrm{P}_{\mathrm{T}}$ & 0.051 PSIA & 0.211 PSIA & 0.069 PSIA & 0.067 PSIA \\
\hline TAE for FE $\mathrm{T}_{\mathrm{T}}$ & $0.52 \mathrm{R}$ & $2.33 \mathrm{R}$ & $0.70 \mathrm{R}$ & $0.61 \mathrm{R}$ \\
\hline
\end{tabular}

\section{Corrected Mass Flow Rate}

A previous study ${ }^{8}$ indicated that the most accurate method of air flow measurement for this experiment was by integration of the measured conditions at the FERRA for test points where a survey was acquired. However the same study indicated that a high spatial data resolution (i.e. a survey) was required for this method to produce the desired accuracy. In this section calculations of the mass flow rates from the snapshot methods, as well as from a curve fit based on a snapshot corrected mass flow and inlet pressures, are compared to the survey corrected mass flow rate.

\section{Methods}

a. Calculation of Corrected Mass Flow Rate from Surveys and Snapshots

As for the calculation of averaged total pressures and total temperatures, the calculation of corrected mass flow rate from the surveys and snapshots followed the method of the surveys. The mass flow rate was calculated at each probe location (or simulated probe location for the enhanced snapshots) as described previously and integrated across the plane.

\section{b. Calculation of Corrected Mass Flow Rate from Curve Fit}

As an alternative approach to determining corrected mass flow rate, pressures from the inlet were used to augment the snapshot mass flow rate. To accomplish this, Design Expert 10 software was used to calculate a curve fit of survey corrected mass flow rate from the unenhanced snapshot corrected mass flow and the average inlet throat static pressure. The average inlet throat static pressure was calculated from the 5 static pressures located around the 
circumference at the inlet throat. These parameters were chosen because they exhibit smooth variations with the survey corrected mass flow rate largely independent of other parameters, as can be seen in the Fig. 24. Note that there is a slight offset between the values with and without the AIP rakes.
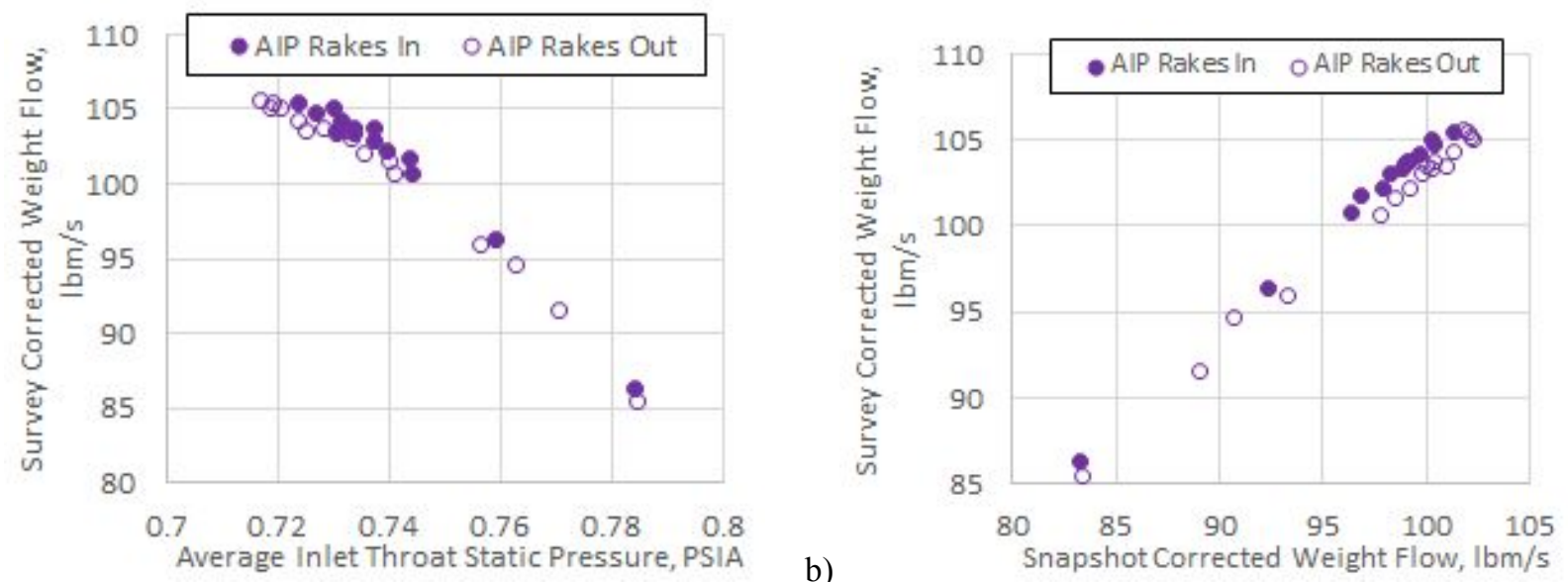

Figure 24. Survey corrected mass flow vs a) static pressure at the inlet throat and b) snapshot corrected mass flow.

\section{Results and Discussion}

\section{a. Corrected Mass Flow Rate from Snapshots}

Errors in the corrected mass flow rate for the selected snapshot processing methods are shown in Fig 25. It can be seen that the unenhanced snapshots underpredict the corrected flow. This is not surprising given that the spacing between the wall and the nearest total pressure probe is large for certain rake types, which causes the total pressure at the wall (i.e. the static pressure) to represent a disproportionately large region in the calculation. In nearly all cases the GI Near method outperformed the PCHIP method, which in turn significantly outperformed the unenhanced snapshots.

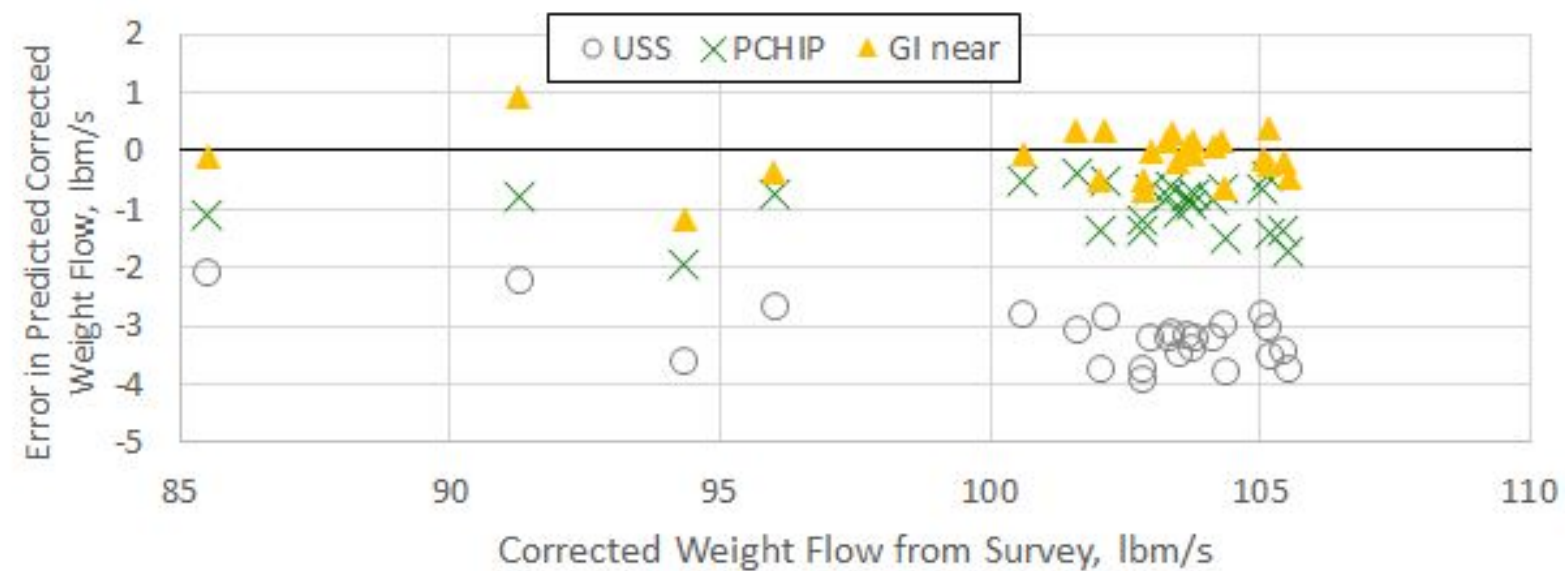

Figure 25. Error in predicted corrected mass flow rate from the down-selected ESSs.

\section{b. Corrected Mass Flow Rate from Curve Fit}

The coefficients and p-values for the curve fit that was developed using the unenhanced snapshot corrected weight flow and the average inlet throat static pressure are shown in Table 5. The analysis showed that there is a statistically significant difference between the corrected mass flow rate with and without the AIP rakes. The presence of the rakes increases the blockage within the propulsor and produces wakes that affect corrected weight flow. The effect appears only as a constant offset, and it can be noted that the values of the coefficients for $\mathrm{W}_{\mathrm{C}, \mathrm{sS}}$, $\mathrm{P}_{\mathrm{S}, \mathrm{IT}}$ and $\mathrm{P}_{\mathrm{S}, \mathrm{IT}}{ }^{2}$ are the same in both cases. 
P-values indicate the estimated probability that there is no effect from a given factor. Typically a value of 0.05 or less is considered significant, i.e. that the factor influences the response with a $95 \%$ confidence level. The p-values for each of the coefficients in the resulting model fall well below this criteria.

The curve fit only uses data with the rakes at 0 degrees, tunnel at Mach 0.78 and incoming boundary layer thickness of 4.8 ", hence it should only be used for those conditions.

Table 5: Corrected mass flow rate coefficients and p-values.

\begin{tabular}{|c|c|c|c|}
\hline No AIP Rakes & With AIP Rakes & $\mathrm{W}_{\mathrm{C}}=$ & $\mathrm{p}$-value \\
\hline-467.9 & -466.7 & constant & -- \\
\hline+0.7197 & +0.7197 & $* \mathrm{~W}_{\mathrm{C}, \mathrm{SS}}$ & $<0.0001$ \\
\hline+1422.0 & +1422.0 & ${ }^{*} \mathrm{P}_{\mathrm{S}, \mathrm{T}}$ & 0.0064 \\
\hline-1011.1 & -1011.1 & ${ }^{*} \mathrm{P}_{\mathrm{S}, \mathrm{IT}}{ }^{2}$ & 0.0017 \\
\hline
\end{tabular}

Figure 26 shows contour plots of the corrected mass flow rate fit as a function of its fundamental factors. As can be seen from the contours, the difference between the "no AIP rakes" and "with AIP rakes" fits do not alter the shape of the contours but rather offset them somewhat.

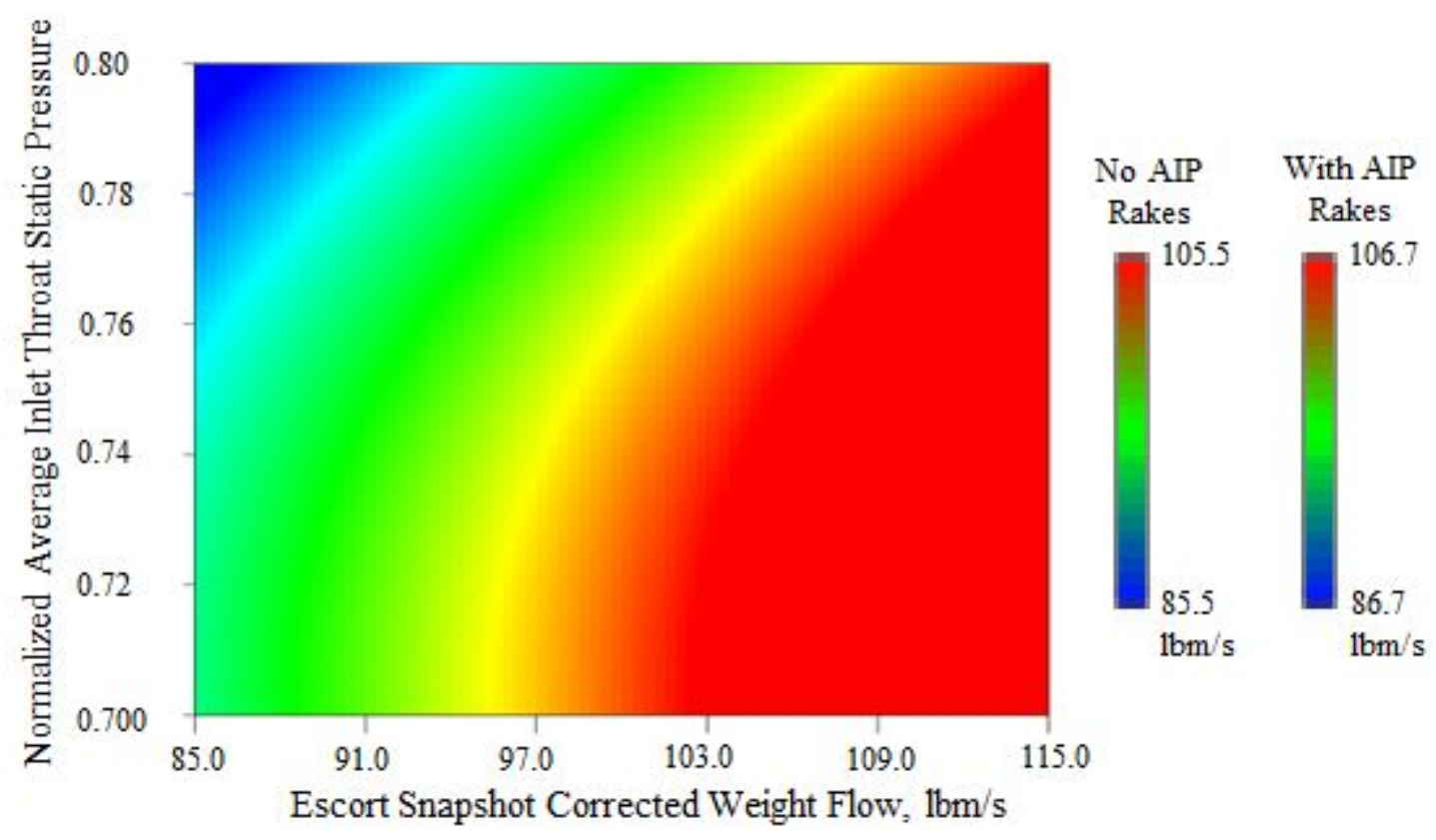

Figure 26. Contour plot of predicted corrected weight flow from the curve fit. Two colorbars are shown to indicate the shift in contours based on the presence of the AIP rakes.

Figure 27 shows the error in the predicted corrected weight flows as a function of the survey corrected weight flow. The unenhanced snapshot data are included for comparison. The fit displays a smaller error range than the unenhanced snapshots, the PCHIP, or the GI Near. It may be expected that since the data used to develop the curve fit are the same data being used to test it, the resulting values are well matched. However, the factors used to develop the curve fit were selected a priori, the number of coefficients in the final curve fit is small compared to the number of data points used to develop the fit, and the p-values indicate that the coefficients are highly significant. These considerations provide good confidence in the validity of the curve fit. 


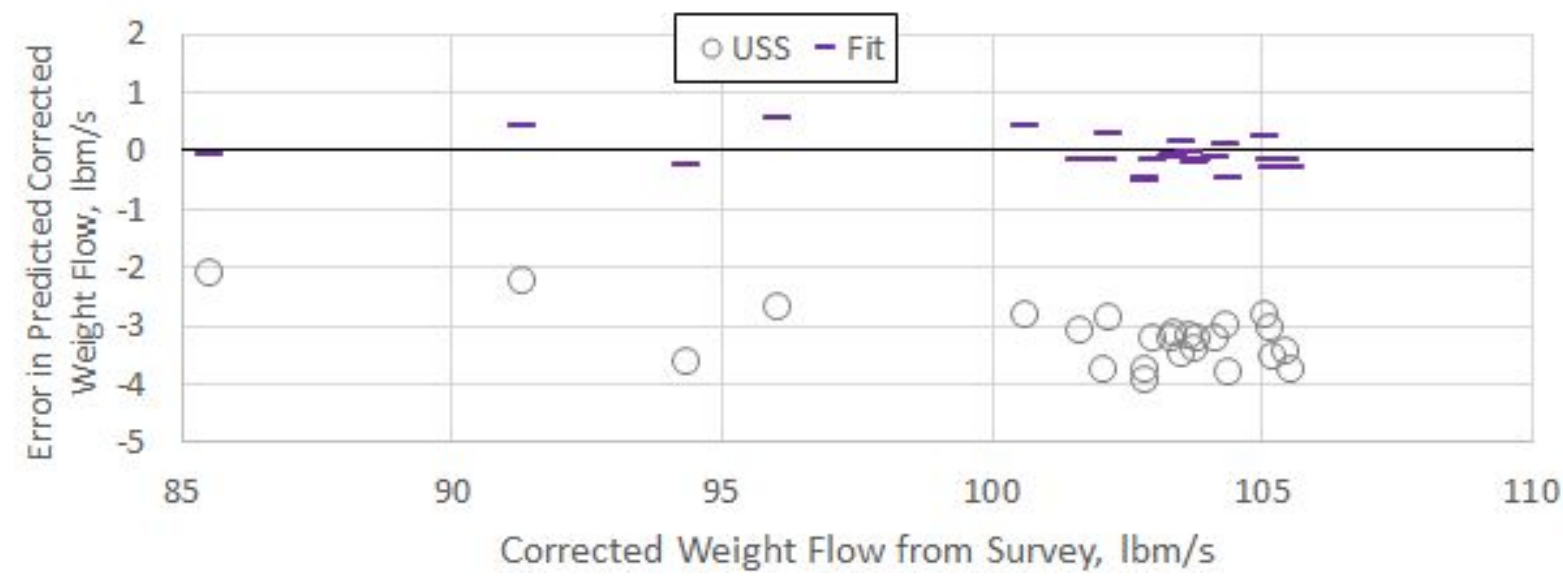

Figure 27. Error in predicted corrected mass flow rate from the curve fit.

c. Summary of Corrected Mass Flow Rate Results

The slopes and $\mathrm{R}^{2}$ values for trend lines of the corrected mass flow rate results with the intercept forced to zero are presented in Fig. 28. For both slope and $\mathrm{R}^{2}$, the curve fit method outperforms all of the snapshot-based methods.

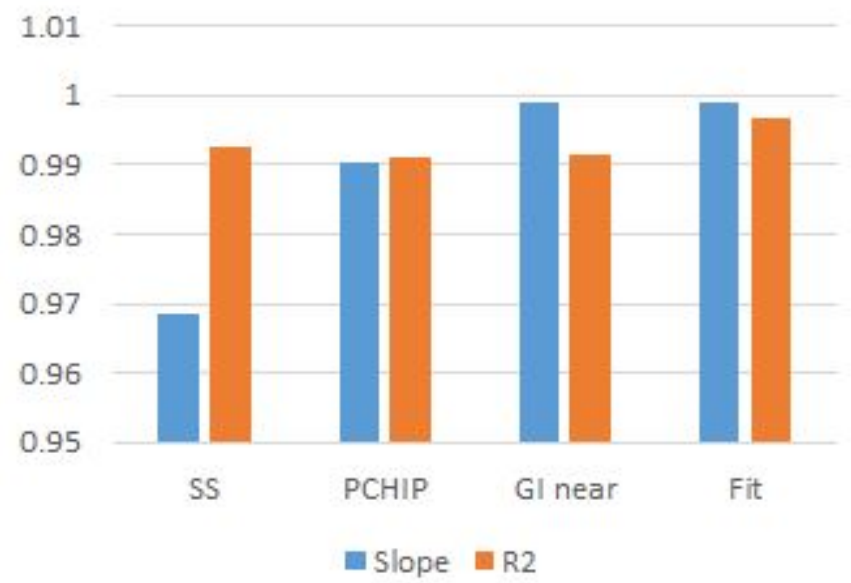

Figure 28. Values of slope and $\mathbf{R}^{2}$ of the trend line of corrected weight flow for each interpolation method.

Table 6 shows the calculated total analytical errors in corrected mass flow predictions for selected data processing methods at the ADP. These results confirm that the curve fit outperforms the other snapshot methods. In addition, calculating the corrected mass flow rate using the curve fit is less computationally intense. For these reasons, the curve fit is considered the preferred method for estimating mass flow in the absence of a full survey.

Table 6. Maximum total analytical errors for corrected mass flow predictions for selected data processing methods.

\begin{tabular}{|c|c|c|c|c|c|}
\hline & Survey $^{8}$ & USS & PCHIP & GI Near & Fit \\
\hline TAE for $\mathrm{W}_{\mathrm{C}}$ & $0.47 \mathrm{lbm} / \mathrm{s}$ & $4.41 \mathrm{lbm} / \mathrm{s}$ & $2.15 \mathrm{lbm} / \mathrm{s}$ & $1.34 \mathrm{lbm} / \mathrm{s}$ & $0.98 \mathrm{lbm} / \mathrm{s}$ \\
\hline
\end{tabular}

\section{Efficiency}

For evaluating the effectiveness of the sparse data enhancement techniques, adiabatic efficiency is the most important test. This is because minimizing the BLI-induced reduction in adiabatic efficiency is a key to a viable BLI propulsor design. Further, at low fan pressure ratio and low fan temperature ratio, adiabatic efficiency is highly sensitive to small changes in the measured pressures and temperatures. 


\section{Methods}

Stage adiabatic efficiency was calculated assuming isentropic compression of an ideal gas with Eq. (1), below.

$$
\eta_{a, s}=\frac{\left(\frac{P_{T, F E R R A}}{P_{T, A I P R A A}}\right)^{\frac{\gamma-1}{\gamma}}-1}{\frac{T_{T, F E R R A}}{T_{T, A I P R R A}}-1}
$$

To apply this equation, the conditions of the AIP and FE must represent the same operating conditions. The method applied to the surveys ${ }^{11}$ was used for the snapshots as well. For calculating efficiency, this method uses curve fits of total pressure and total temperature at the AIP as a function of the weight flow corrected to freestream conditions. The curve fits provide AIP total pressure and total temperature even for conditions at which no AIP measurements were made. It should be noted that for the current work, only fan stage efficiency was measured.

\section{Results and Discussion}

Results for the downselected enhancement methods and the unenhanced snapshots are shown in Figs. 29 and 30. For constant exit-corrected flow (Fig 29), GI Near performs the best at most fan speeds near the ADP. PCHIP performs as well or better for lower fan speeds. While all methods are less accurate at low fan speeds, both enhancement methods perform significantly better than the unenhanced snapshot in this regime. For the $100 \%$ speed line (Fig. 30), GI Near performs better than PCHIP and unenhanced snapshots for nearly all cases. All methods appear to suffer from reduced accuracy farther from the ADP on the choked side, although the degraded accuracy is much smaller than for low fan speeds in the previous figure. The common factor in the regions mentioned (i.e., low fan speed and high exit corrected flow) is that these are the areas where pressure and temperature ratios are lower, causing the adiabatic efficiency to be more sensitive to errors in those parts of the fan map.

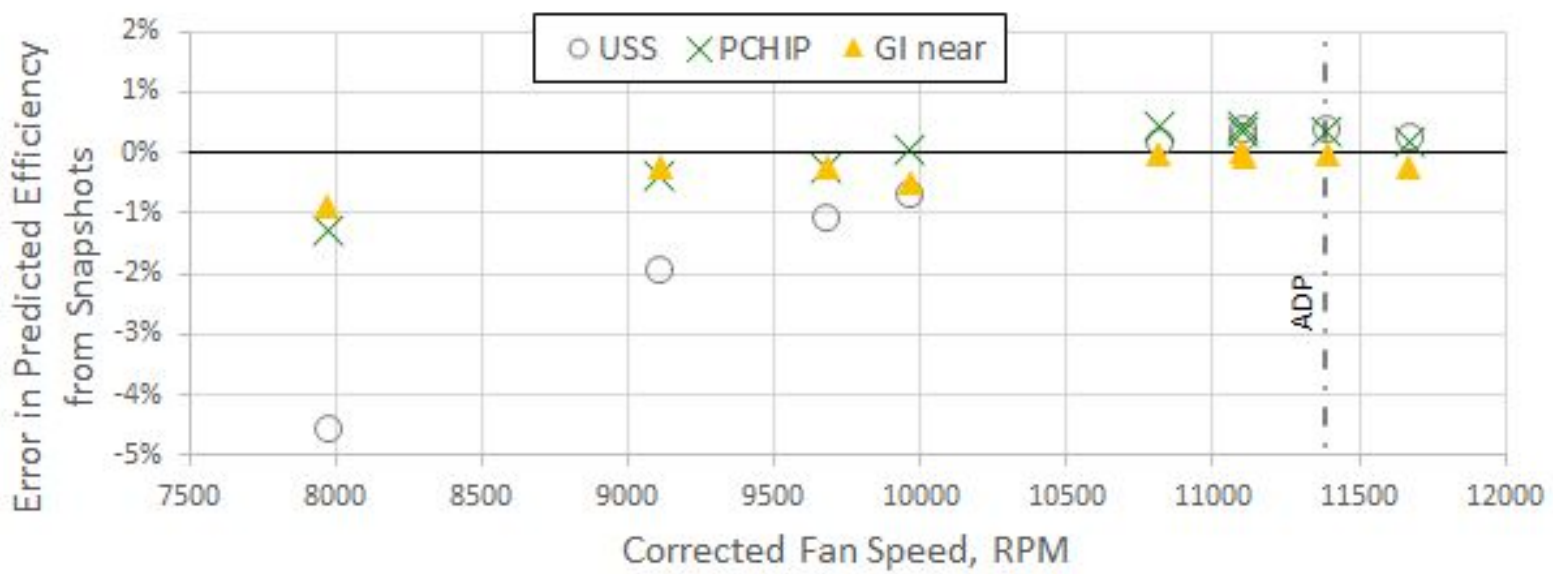

Figure 29. Error in predicted efficiency from the down-selected ESSs for constant exit-corrected flow. 


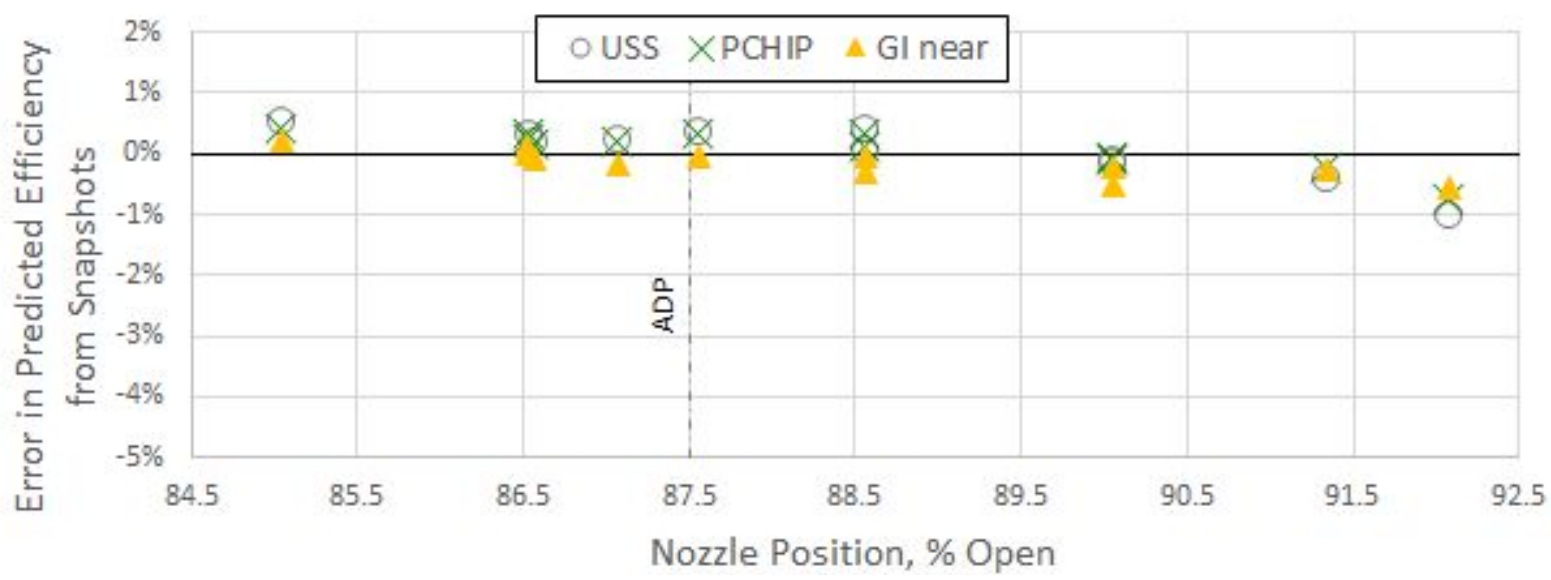

Figure 30. Error in predicted efficiency from the down-selected ESSs for the $100 \%$ speed line.

Figure 31 presents the slope and $\mathrm{R}^{2}$ for fan-stage adiabatic efficiency. The results show that the PCHIP method has on average the best efficiency estimate of the enhanced snapshot methods, the GI Near method has the best repeatability. It is interesting to note that the GI Near method, which predicted the FE $\mathrm{P}_{\mathrm{T}}$ flowfield better than the standard interpolation methods or the unenhanced snapshot method, and generally did a much better job predicting elements of the performance when compared to the unenhanced snapshot method, nevertheless did no better than the unenhanced snapshot method as measured by the slope of the efficiency trend line. However, the authors would be more confident predicting the performance with either the PCHIP or GI Near methods due to the significant improvement in $\mathrm{R}^{2}$.

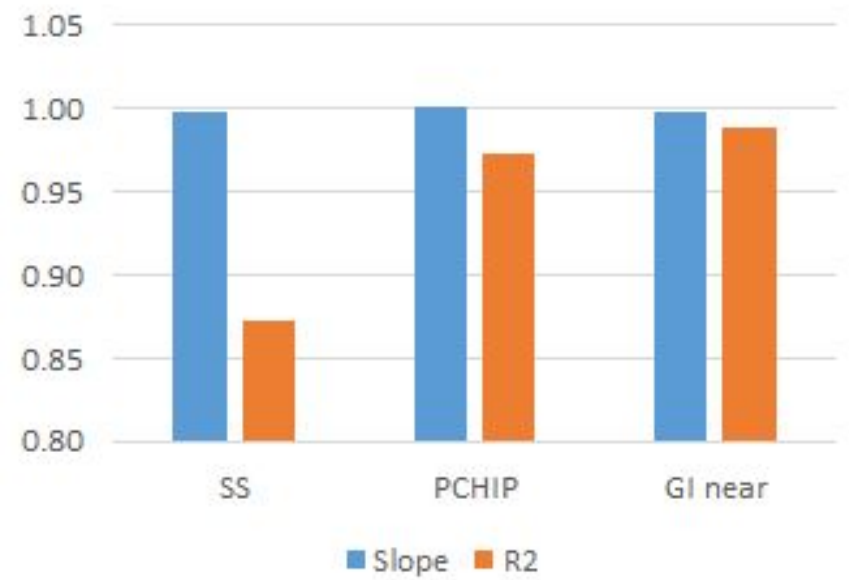

Figure 31. Values of slope and $R^{2}$ of the trend line of efficiency for each interpolation method.

Table 7 shows the calculated total analytical errors for efficiency predictions for selected data processing methods at the ADP. It can be seen that using the unenhanced snapshot doubles the TAE for the calculation of efficiency compared to the survey. The use of enhancement techniques reduced the error significantly, bringing the predicted adiabatic efficiencies much closer to those from the surveys.

The surveys met the original fan-stage adiabatic efficiency requirement of $\pm 1.5 \%$ uncertainty needed to assess the cruise performance of the BLI'DTF propulsor relative to the predictions. For other purposes, the needs are somewhat less stringent, although certainly the lower the total error, the better. Overall, the results support the hypothesis that appropriate enhancement methods can reduce the error of performance measurements and that the errors are small enough to be of practical use. In general, from the range of conditions tested the efficiency predictions were most accurate on the stall side of the nominal operating line, and at higher fan speeds. For most parts of the fan map we can use our technique with confidence, as the shapes of the $\mathrm{P}_{\mathrm{T}}$ and $\mathrm{T}_{\mathrm{T}}$ contours will not change dramatically from point to point. However, the authors caution that the ability of these methods to predict 
fan performance at reasonable error levels in areas of unsteady phenomena such as stall or flutter (which were observed during the experiment) and areas with significant separation in the inlet (not observed in the experiment) is unproven.

Table 7. Total analytical error in adiabatic efficiency for selected data processing methods.

\begin{tabular}{|c|c|c|c|c|c|}
\hline \multicolumn{2}{|c|}{} & Survey $^{8}$ & USS & PCHIP & GI Near \\
\hline \multirow{2}{*}{ TAE for $\eta_{\mathrm{a}, \mathrm{s}}$} & Maximum & $3.1 \%$ & $5.0 \%$ & $3.4 \%$ & $3.2 \%$ \\
\cline { 2 - 6 } & ADP & $1.3 \%$ & $3.5 \%$ & $2.0 \%$ & $1.7 \%$ \\
\hline
\end{tabular}

Based on the results, one might conclude that the GI Near method is the preferred method because it obtains TAE levels that are slightly better than the PCHIP and also produces an enhanced snapshot flow field that is most like the original experiment. However, with the current data set confined to two orthogonal lines of data, there is some concern that the GI Near method will not perform well at conditions that are far from those lines. Thus, for the current data set, the authors recommend using the PCHIP method in parallel with GI Near and apply engineering judgement where the two methods disagree. Applying these methods to the 119 snapshots measured at various conditions will enhance our understanding of this fan. While the results are no substitute for the richer set of data available from the 20 surveys, these results can supplement the survey data. The error and uncertainty results will be used to make recommendations on operating conditions at which to take surveys during subsequent test entries.

\section{Conclusions}

The enhanced snapshot approach shows promise toward addressing those conditions not covered by survey data for the $\mathrm{BLI}^{2} \mathrm{DTF}$ data set. At those conditions an estimate of fan stage performance can be calculated for modest increases in error and uncertainty.

For the AIP total pressure and total temperature, all of the techniques including the USS did relatively well with uncertainties similar to those for the full surveys. The only slight anomaly is a bias seen for the biCS method in AIP total pressure although even that was minor.

For the FE total pressure and total temperature, it was clear that the USS was not sufficient with errors $5\left(\mathrm{P}_{\mathrm{T}}\right)$ to $6\left(\mathrm{~T}_{\mathrm{T}}\right)$ times higher than for the full survey. All of the snapshot enhancement techniques reduced the error levels, with PCHIP and GI performing best overall. BiCS had statistic quantities nearly on par with these front-running techniques, but artifacts in the contours made it unfavorable.

The mass flow calculated from the USS matches the full survey results poorly, exhibiting high bias errors across the range of survey points. The ESS methods perform better. The curve fit does the best and is the least computationally intense making it useful for real time data processing in subsequent tests.

For adiabatic efficiency, PCHIP and GI Near exhibit TAE levels close to those of the survey. While we would likely not have been satisfied with these levels for the ADP, they seem adequate to gain some insight into the fan map that was acquired. The adiabatic efficiency prediction accuracy of all methods is reduced in areas on the fan map where pressure and temperature ratios are lower, that is at low fan speed and high exit corrected flow. This is expected, as adiabatic efficiency is more sensitive to errors in those parts of the fan map.

Based on the results, it is recommended that the PCHIP and GI Near methods be used in parallel, applying engineering judgement where the two methods disagree. This will expand the range of conditions for which performance assessments can be made, albeit with a greater error rate.

\section{Acknowledgements}

This effort was supported by NASA's Advanced Air Transport Technology Project. The authors gratefully acknowledge the support of the many additional people who made this work possible, including the 8'x6' Supersonic Wind Tunnel facility staff, NASA's design and manufacturing teams, and our team members at UTRC and Arnold Engineering Development Complex.

\section{References}


1 Kawai, R. T., Friedman D. L., and Serrano, L., "Blended Wing Body (BWB) Boundary Layer Ingestion (BLI) Inlet Configuration and System Studies," NASA/CR 214534, 2006.

2 Plas, A., Crichton, D., Sargeant, M., Hynes, T., Greitzer, E., Hall, C., and Madani, V., "Performance of a Boundary Layer Ingesting (BLI) Propulsion System," 45th AIAA Aerospace Sciences Meeting and Exhibit, AIAA Paper 2007-0450, Aug. 2007.

3 Hardin, L. W., Tillman,G., Sharma, O. P., Berton, J., and Arend, D. J., "Aircraft System Study of Boundary Layer Ingesting Propulsion," in 48th AIAA/ASME/SAE/ASEE Joint Propulsion Conference, Atlanta, Georgia, 2012, AIAA-2012-3993.

4 Arend, D. J., Tillman, G., and O'Brien, W. F., "Generation After Next Propulsor Research: Robust Design for Embedded Engine Systems," in 48th AIAA/ASME/SAE/ASEE Joint Propulsion Conference, Atlanta, Georgia, 2012, AIAA-2012-4041.

5 Bakhle, M. A., Reddy, T. S. R., Herrick, G. P., Shabbir, A., and Florea, R., "Aeromechanics Analysis of a Boundary Layer Ingesting Fan," in 48th AIAA/ASME/SAE/ASEE Joint Propulsion Conference, Atlanta, Georgia, 2012, AIAA-2012-3995.

6 Florea, R. V., Matalanis, C., Hardin, L. W., Stucky, M., and Shabbir, A., "Parametric Analysis and Design for Embedded Engine Inlets," in 48th AIAA/ASME/SAE/ASEE Joint Propulsion Conference, Atlanta, Georgia, 2012, AIAA-2012-3994.

7 Arend, D. J., Wolter, J. D., Hirt, S. M., and Provenza, A. J., "Experimental Evaluation of the Performance and Operability of a Large-Scale Boundary Layer Ingesting Propulsor for Highly Efficient Subsonic Cruise Aircraft," 53rd AIAA/ASME/SAE/ASEE Joint Propulsion Conference, Atlanta, Georgia, AIAA-2017-5041, 2017.

8 Wolter, J. D., Arend, D. J., and Hirt, S. M., "Development of a Rotating Rake Array for Boundary-LayerIngesting Fan-Stage Measurements," in 53rd AIAA/ASME/SAE/ASEE Joint Propulsion Conference, Atlanta, Georgia, AIAA-2017-4636, 2017.

9 Hirt, S. M., Arend, D. J., Wolter, J. D., and Johnson, A., "Development of a Flow Field for Testing a Boundary- Layer-Ingesting Propulsor," in 53rd AIAA/ASME/SAE/ASEE Joint Propulsion Conference, Atlanta, Georgia, AIAA-2017-5043, 2017.

10 Cousins, W. T., Voytovych, D., Tillman, G., and Gray, E., "Design of a Distortion-Tolerant Fan for a Boundary-Layer Ingesting Embedded Engine Application," in 53rd AIAA/ASME/SAE/ASEE Joint Propulsion Conference, Atlanta, Georgia, AIAA-2017-5042, 2017

11 Hardin, L. W., Cousins, W. T., Wolter, J. D., Arend, D. J., and Hirt, S. M., "Data Analysis Techniques for Fan Performance in Highly-Distorted Flows from Boundary Layer Ingesting Inlets," in 56th Aerospace Sciences Meeting, Orlando, Florida, 2018.

12 de Boor, C., A Practical Guide to Splines. Springer-Verlag, New York: 1978.

13 Fritsch, F. N. and Carlson, R. E., "Monotone Piecewise Cubic Interpolation." SIAM Journal on Numerical Analysis. Vol. 17, 1980, pp.238-246.

14 White, G. W., "Basics of Estimating Measurement Uncertainty," Clin Biochem Rev. Vol 29 Suppl, 2008, pp.S53-S60. 